\title{
Las exportaciones y el crecimiento económico en Boyacá Colombia 1980-2015*
}

\author{
Exports and Economic Growth \\ in Boyacá Colombia 1980-2015
}

As exportações e o crescimento econômico em
Boyacá Colômbia 1980-2015

Willyam Cáceres Rodríguez **

Omaira Inés Agudelo Cely ${ }^{* * *}$

Ricardo Alonso Tejedor Estupiñán ${ }^{* * * *}$

DOI: https://doi.org/10.19053/01203053.v37.n65.2018.7122

Fecha de recepción: 26 de julio de 2017

Fecha de aprobación: 6 de diciembre de 2017

\footnotetext{
* Este artículo corresponde a los resultados obtenidos en el proyecto código 2012107 "Impacto de las exportaciones del departamento de Boyacá en su producto interno bruto entre 1980 y 2010", financiado por la Universidad Antonio Nariño, Bogotá, Colombia.

** Magíster en Ciencias Económicas, Universidad Nacional de Colombia, Bogotá. Profesor asistente e investigador de la Universidad Antonio Nariño. Colombia. Correo electrónico: cacer70@yahoo.com (D) http://orcid. org/0000-0003-1066-6028

*** Economista, especialista en Administración Pública y estudiante de Maestría en Historia, Universidad Pedagógica y Tecnológica de Colombia. Profesora asistente e investigadora de la Universidad Antonio Nariño. Colombia. Correo electrónico: omairainesa@yahoo.com (iD) https://orcid.org/0000-0002-7932-

**** Magister en Economía. Investigador Grupo Modeal Universidad Pedagógica y Tecnológica de Colombia UPTC, Colombia. Dirección postal: Av. Central del Norte, UPTC, Tunja, Edificio Central, Oficina C-342a. Teléfono: +57 3214609895. Correo Electrónico: ricardotse@hotmail.com (D) orcid.org/0000-0002-5877-846X.
} 


\section{Resumen}

Este artículo analiza la relación entre el crecimiento del producto interno bruto y las exportaciones del departamento de Boyacá durante el período 1980-2015. Se encuentra evidencia para validar la hipótesis que afirma que el crecimiento económico está fuertemente influenciado por las exportaciones. Se utiliza un modelo econométrico de series de tiempo (VAR). Los resultados obtenidos a través de la aplicación de las pruebas de cointegración de Johansen y causalidad de Granger indican que las exportaciones industriales principalmente $y$, en menor medida, las exportaciones primarias causan impactos positivos en el producto neto de exportaciones. Las pruebas de impulso respuesta también corroboran dicha relación. Lo anterior confirma la importancia que tiene el comercio exterior como medio para potenciar las ventajas comparativas que ofrece la oferta exportadora del departamento de Boyacá.

Palabras clave: economía regional, crecimiento, exportaciones primarias, exportaciones industriales, tipo de cambio.

Clasificación JEL: R11, O47, O13, 014, F31. 


\section{Abstract}

This article analyses the relationship between Boyacá's gross domestic product and its exports from 1980 to 2015 . Evidence is found to validate the hypothesis that affirms that economic growth is strongly influenced by exports. A time series econometric model (VAR) is used. The results obtained through the application of the Johansen cointegration test and the Granger causality test indicate that mainly industrial exports and, to a lesser degree, primary exports, cause a positive impact on the gross product of exports. The impulse-response tests also corroborate this relation. The above confirms the importance of foreign trade as a means of enhancing the comparative advantages that Boyacá's export supply offers.

Keywords: regional economy, growth, primary exports, industrial exports, exchange rate. 


\section{Resumo}

Este artigo analisa a relação entre o crescimento do produto interno bruto e as exportações do departamento de Boyacá durante o período de 1980 a 2015. Existem fundamentos para confirmar a hipótese de que o crescimento económico é fortemente influenciado pelas exportações. Utiliza-se um modelo econométrico de sequências temporais (VAR). Os resultados obtidos através da aplicação dos testes de cointegração de Johansen e de causalidade de Granger indicam que as exportações industriais, principalmente, e em menor grau as exportações primárias, causam impactos positivos no produto neto das exportações. Os testes de impulso/resposta também corroboram esta relação. $\mathrm{O}$ anterior confirma a importância do comércio exterior como meio de potenciar as vantagens comparativas fornecidas pela oferta exportadora do departamento de Boyacá.

Palavras chave: economia regional, crescimento, exportações primárias, exportações industriais, tipos de trocas. 


\section{INTRODUCCIÓN}

El estudio de los factores que contribuyen al crecimiento económico, particularmente el rol del comercio exterior (en su componente de exportaciones), ha sido objeto de análisis por parte de la teoría económica. Autores de la talla de Smith, Ricardo, Kalecki, Kaldor y Thirwall, entre otros, han coincidido en señalar que el intercambio comercial le permite a un país o región incrementar su nivel de producción e ingreso relativos. Las políticas orientadas a incentivar el sector exportador permiten la asignación de los recursos según las ventajas comparativas de los países, al igual que una mayor utilización de la capacidad productiva y ampliación de las economías de escala (Balassa, 1985).
En los años noventa del siglo pasado, la implementación del proceso de apertura económica en Colombia, a través de una serie de medidas relacionadas con la liberalización comercial, del mercado de capitales y la flexibilización del mercado laboral, pretendió encaminar a la economía por una senda de mayor crecimiento. Las anteriores reformas estructurales y, particularmente, las relacionadas con el comercio exterior, buscaban remover los obstáculos a la competitividad internacional de la producción nacional. Por tanto, eliminar el sesgo antiexportador se convirtió en un objetivo prioritario de la política comercial.

Pese a las bajas tasas de crecimiento del PIB del departamento de Boyacá (por debajo del promedio nacional), el sector exportador ha tenido un mejor 
desempeño y ha respondido positivamente a las exigencias de una economía más expuesta al comercio exterior. Según Sánchez y Rocha (2000), Boyacá es un departamento con vocación exportadora, tal como lo refleja la participación de las exportaciones sobre el PIB, la cual está por encima del promedio nacional. No obstante, la cercanía a los grandes centros de demanda (especialmente Bogotá, Medellín y Cali) hace que la producción de Boyacá esté dirigida principalmente al mercado nacional y, en menor medida, al mercado internacional.

Si bien Boyacá es un departamento con vocación agrícola y minera, el sector servicios contribuye con más del $50 \%$ del producto departamental. La oferta exportable la componen bienes de origen primario e industrial. Esmeraldas, carbón, flores, papa, fabricación de máquinas, aparatos y material eléctrico, motores para automóviles y muebles artesanales, son los productos con mayor presencia en los mercados internacionales. Igualmente existe una participación bastante significativa en las exportaciones totales de solo dos productos, esmeraldas y carbón. Llama la atención que siendo un departamento que abastece el mercado nacional con productos del sector primario, este hecho no se refleje en una mayor participación en las exportaciones agrícolas y agroindustriales.
En un esfuerzo por analizar la relación entre las exportaciones y el crecimiento del departamento de Boyacá, el propósito del artículo se centra en verificar si son las exportaciones las que impactan positivamente el PIB departamental o, por el contrario, el crecimiento es el que influye en el dinamismo de las exportaciones. La anterior pregunta se conoce en la literatura internacional como la hipótesis de crecimiento liderado por exportaciones "export led growth" (ELG, por sus siglas en inglés). Para ello se desagregan las exportaciones totales en primarias y manufacturas. Esta desagregación obedece a que la mayoría de los bienes exportados proviene de dichos sectores. Igualmente, el documento presenta una descripción bastante detallada de los sectores exportadores del departamento.

El artículo está dividido en cinco secciones. En la primera sección se abordan los aspectos teóricos referentes al comercio y el crecimiento económico; en la segunda sección se revisan algunos estudios empíricos que analizan la relación entre exportaciones y crecimiento para algunos países y también para Colombia. En la tercera sección se hace una descripción del comportamiento de las exportaciones por sectores económicos; posteriormente, a partir de la información disponible, se analizan los datos a través de un modelo econométrico con sus respectivas pruebas y, en último término, se sugieren algunas conclusiones. 


\section{VÍNCULOS ENTRE COMERCIO Y CRECIMIENTO ECONÓMICO. ASPECTOS TEÓRICOS}

El comercio e intercambio entre naciones es una práctica bastante común, que con la profundización del libre comercio y la globalización se ha generalizado en todo el mundo. Efectivamente, existen vínculos entre el comercio $\mathrm{y}$ el crecimiento económico que han sido bien estudiados por la teoría económica. David Ricardo expone las bondades del intercambio utilizando el análisis de la ventaja comparativa.

Así, pues, el comercio exterior, si bien es muy beneficioso para un país, toda vez que aumenta la cantidad y variedad de los objetos en que pueden gastarse las rentas y proporciona incentivos al ahorro y a la acumulación del capital, por la abundancia y baratura de las mercancías, no tiende a hacer subir los beneficios del capital, a menos que los artículos importados sean de primera necesidad para el trabajador. [...] En un sistema de comercio perfectamente libre, cada país naturalmente, dedica su capital y trabajo a los empleos que le son más beneficiosos. Esta tendencia a la ventaja individual está admirablemente relacionada con el bien universal del mundo. (Ricardo, 1985, pp.137-138)

El grado y la cantidad de factores productivos que posee un país, junto con el tamaño del mercado y el nivel de especialización de la industria, hacen que una nación pueda disfrutar de una mayor cantidad de bienes y servicios, incrementando sus niveles de producto y empleo. La especialización implica, no solamente, dedicar recursos a aquellas actividades y labores donde se posean ventajas relativas, reflejadas en menores precios, sino poder ampliar la producción hacia los mercados extranjeros a través del comercio exterior. Por tanto, la captura de mercados foráneos depende de la forma como se adecue la estructura productiva a las ventajas (si las tiene) en mano de obra, recursos naturales y capital, frente al país o países con los que se quiera comerciar.

El famoso economista sueco Bertil Ohlin expone en forma clara las ventajas del comercio y la especialización productiva:

Si un país tuviera que fabricar todo lo que necesita para sí mismo, la producción, por lo menos en la mayoría de los países, podría hacerse en pequeña escala. Un país como Suecia no necesita muchos centenares de miles de coches al año, ni tampoco grandes cantidades de tractores, presas, aviones, etc. Hay artículos de los que tal vez no se vende siquiera uno al año en nuestro país, que es relativamente pequeño.... Es evidente que la fabricación en Suecia de tales artículos resultaría mucho más cara que en una gran fábrica que los produce para el mercado mundial. Un automóvil 
Ford costaría, tal vez, dos o tres veces más de lo que efectivamente cuesta ahora. Es, por tanto, una ventaja para todos que Suecia se especialice en la fabricación de teléfonos, separadoras, rodamientos a bolas, transformadores eléctricos y algunos otros artículos de maquinaria, en lugar de dedicarse a la producción de todo dentro del ramo de la maquinaria. Exportando estos artículos se consigue la posibilidad para el país de pagar su importación de automóviles y prensas, por ejemplo. (Ohlin, 1948, p. 6)

La insuficiencia del mercado interno para absorber la oferta disponible, abre la posibilidad para que a través del comercio, las naciones propendan a mayores niveles de producción e ingreso. Es así que las exportaciones actúan como mecanismo para ampliar la demanda agregada. Al respecto Adam Smith señala:

Gracias al comercio exterior, la limitación del mercado doméstico no impide que la división del trabajo, en una rama particular de las artes y de las manufacturas, sea llevada hasta su máxima perfección. Abriendo un mercado más amplio para cualquier porción del producto del trabajo que exceda las necesidades de consumo doméstico, lo estimula para perfeccionar y fomentar las fuerzas productivas, de suerte que alcance un desarrollo considerable del producto anual y, por consiguiente, la riqueza y la renta efectiva de la sociedad. (Smith,1994, p. 394)
Michal Kalecki (1977) enfatiza en el rol que juega el comercio exterior como determinante del nivel de empleo y producción de un país. Su análisis en la determinación del producto es eminentemente de demanda. El incremento en las ganancias de los capitalistas no depende solamente de la inversión bruta, del consumo y los gastos gubernamentales, sino del saldo positivo de la balanza comercial. Por tanto, la búsqueda de nuevos mercados que permitan ampliar los excedentes de exportaciones, repercutirá favorablemente en el proceso de acumulación de capital de aquellas naciones que lo practiquen.

Desde América Latina, organismos de reconocida reputación como la Comisión Económica para América Latina y el Caribe (CEPAL), han hecho aportes significativos tanto en el ámbito teórico como empírico, a la relación entre el crecimiento económico y el sector externo (especialmente la importancia del sector exportador). El proceso de apertura económica iniciado en la región desde los años setenta y especialmente en la década de los ochenta, obligó a dar un giro significativo en torno a la manera como se aplicaba la política económica en pro de mayores tasas de crecimiento en las economías de la región y la mayor exposición del aparato productivo a la competencia internacional. De hecho, un sector exportador dinámico aportaría elementos significativos para el crecimiento de la 
economía. En tal sentido, la CEPAL afirma:

Las exportaciones pueden contribuir a incrementar el ritmo de crecimiento económico de un país por: i) la generación de divisas que permitan adquirir las importaciones necesarias para la expansión económica; ii) el aprovechamiento de economías de escala y de especialización, derivadas de la ampliación de los mercados a los cuales las empresas locales destinan su producción; iii) los efectos positivos o encadenamientos que la actividad exportadora tiene en otras actividades, que permiten aumentar la utilización de recursos materiales y humanos insuficientemente utilizados o que estimulan nuevas inversiones; iv) la reasignación de recursos hacia actividades y empresas de mayor productividad, con el consecuente incremento de la productividad media de la economía; y v) la existencia de un mayor contacto con la economía internacional y con las exigencias de competitividad que enfrentan las actividades exportadoras y sus proveedores. (Comisión Económica para América Latina y el Caribe [CEPAL], 2004, p. 178)

\section{Exportaciones y crecimiento regional}

El interés por el avance en la teoría del crecimiento regional hace su aparición tardíamente hacia comienzos de los años veinte del siglo pasado, básicamente porque el centro de atención de los teóricos del crecimiento estaba enfocado en el ámbito nacional.
Identificar variables y desarrollar modelos que dieran cuenta del crecimiento agregado era la prioridad en aquel entonces. No obstante, la preocupación por el desempleo entre regiones, las marcadas diferencias en un mismo país entre territorios ricos y regiones pobres, al igual que en los niveles de ingreso y producto motivaron la aparición de teorías y modelos que explicaran la dinámica y el comportamiento de dichos fenómenos.

Richardson resume en forma notable los aportes teóricos en materia de crecimiento regional, destacando los planificadores urbanos con sus análisis de la renta regional como función de las exportaciones de la región, modelo conocido como "base exportación". También se destacan los aportes de Ohlin sobre el comercio interregional (1948). Posteriormente, en los años cincuenta sobresalen los aportes de Myrdal (1959) con su teoría de la "causación acumulativa", que tuvo gran influencia en los estudios de crecimiento regional. Igualmente descuellan estudios descriptivos sobre convergencia regional, en términos del ingreso per cápita regional para los Estados Unidos, en cabeza de Kuznets (1973).

Si bien los avances teóricos en materia de crecimiento regional se han visto influenciados por los desarrollos teóricos de los modelos de crecimiento agregado neoclásicos, traslapar los supuestos e hipótesis del 
modelo neoclásico al contexto regional no es lo más adecuado. En este aspecto, Richardson expone:

Las hipótesis básicas de la teoría del crecimiento neoclásica no son aplicables a la economía regional. Por ejemplo, la hipótesis de pleno empleo no es generalmente adecuada para la economía regional, ya que con ella surge un gran número de problemas como resultado de las diferencias interregionales en el grado de utilización de los recursos, particularmente la mano de obra. Asimismo, la competencia perfecta no puede darse por supuesta en el análisis económico regional porque el espacio en sí y la existencia de costes de transporte limitan la competencia; el oligopolio, el monopolio puro o la competencia monopolística son estructuras de mercado mucho más apropiadas. (Richardson, 1977, p. 28)

Por su parte, Kaldor afirma que para que el crecimiento se mantenga a una tasa adecuada se necesita que las industrias básicas (por ejemplo, las del hierro, acero, cemento, construcción y maquinaria) crezcan en mayor medida que las industrias del resto de la economía, de tal manera que los recursos destinados a las industrias productoras de bienes de capital sean mayores, en proporción, a los dirigidos a los sectores de bienes de consumo; lo que se conoce como la teoría del crecimiento desequilibrado. Por tanto, habría más ímpetu en acelerar y desarrollar algu- nos sectores de la industria básica, no solamente para abastecer el mercado interno, sino también el mercado externo; es decir, potenciar industrias manufactureras de exportación. Al respecto afirma Kaldor:

Es indudable que la mayor parte de los países subdesarrollados obtendría mejores resultados tanto en lo que concierne al nivel general de eficiencia y del ingreso real, como a la flexibilidad, si se esforzasen más por incrementar sus exportaciones en vez de producir sustitutos para toda clase de importaciones. La producción de artículos exportables es sin duda mucho más valiosa que la de bienes que sustituyen a otros del exterior, pues los primeros como el comodín de la baraja- pueden ser intercambiados por cualquier clase de producto gracias al comercio internacional. (Kaldor, 1961, p. 48)

En la actualidad cobra importancia observar el crecimiento particular de las regiones y no solamente del país en su totalidad, debido a las notables diferencias en el nivel de desarrollo entre las mismas. En Colombia hay departamentos con altos niveles de pobreza y bajos niveles de ingreso, poco interconectados a los mercados nacionales y sobre todo a los mercados internacionales. La literatura posterior a la Segunda Guerra Mundial sobre crecimiento regional hacía énfasis en los factores de demanda para explicar el crecimiento. Tal es el 
caso de los modelos llamados "base exportación", donde se destaca el rol de las exportaciones en la trayectoria del producto. Al respecto acota $\mathrm{Ri}-$ chardson:

El modelo de renta más simple y más característico -en el sentido de que se utiliza sólo en un contexto regional y urbano - es el de base exportación. Su hipótesis fundamental -que la renta regional es función de las exportaciones de la región (es decir, de las ventas de la región al exterior) -tiene la virtud de enfatizar: la importancia de la "apertura" en el análisis de las economías infranacionales, la interdependencia entre las diferentes zonas de un país y el principio de que lo que ocurre dentro de una región depende crucialmente de lo que ocurre más allá de sus fronteras. (Richardson, 1986, p. 67)

Lo anterior no quiere decir que el crecimiento de una región solo dependa de la variable exportaciones, obviamente depende de muchas otras. Por ello es importante recalcar el hecho de que el comercio exterior juega un papel importante y relevante hoy en día, especialmente en un mundo donde proliferan los tratados de libre comercio, hecho que no ha sido ajeno a Colombia. De ahí la necesidad de determinar la importancia del sector exportador y su incidencia en el crecimiento del departamento de Boyacá.
EXPORTACIONES Y CRECIMIENTO ECONÓMICO EN EL ESCENARIO NACIONAL E INTERNACIONAL

En el ámbito internacional proliferan los estudios que han testeado la relación entre exportaciones y crecimiento; pero dependiendo de la técnica econométrica utilizada (series de tiempo y datos de panel), los resultados han sido diversos en favor y en contra del efecto que el crecimiento de las exportaciones pueda tener sobre el PIB.

En uno de los primeros análisis para un grupo de países en desarrollo, Balassa (1978) destaca que las políticas orientadas a incrementar las exportaciones han conducido a un mayor crecimiento del producto, debido básicamente a la exposición de la producción nacional a la competencia internacional, a las mayores economías de escala y al incremento de la capacidad instalada de la economía. En esta misma línea, Feder (1982) también corrobora, para varios países semiindustrializados, que el crecimiento puede ser generado no solo por aumentos en los niveles agregados de mano de obra y capital, sino también por la reasignación de recursos existentes del sector no exportador menos eficiente al sector de exportación de mayor productividad.

Por su parte, Cuadros (2000), en un estudio entre 1983 y 1997, no encontró 
evidencia a favor de la hipótesis de crecimiento impulsado por exportaciones para México. Chile es un caso exitoso de crecimiento dirigido por el sector exportador y lo han confirmado diversos estudios, en especial Agosín (1999) analiza el período 1960-1995 y mediante un modelo de series de tiempo corrobora la estrecha relación entre el crecimiento del producto y el dinamismo del sector exportador.

Si bien la mayoría de los estudios utilizan datos en un nivel agregado, también existen estudios del ámbito regional o provincial dentro de los países, tal es el caso de Pardo y Meller (2002), quienes demuestran en un estudio para algunas regiones de Chile, que aquellas que están más orientadas al comercio y las exportaciones, tienden a elevar en mayor medida el producto per cápita de estado estacionario en comparación con el resto de regiones. Jin (2002) también analiza el rol de las exportaciones de las cuatro provincias más grandes de Corea del Sur — esto es, en el orden regional- y encuentra sustento a la hipótesis de crecimiento liderado por exportaciones en todas las provincias.

Por su parte, Prime y Park (1997) analizando 26 provincias en China encuentran que en las provincias costeras, las exportaciones han contribuido al crecimiento de los ingresos de dichas regiones, en contraste con las provincias más alejadas de las costas donde la relación entre exportaciones $\mathrm{y}$ crecimiento ha sido relativamente baja. Esta situación la corrobora Ljungwall (2006) al tomar una muestra de 27 provincias en China y probar que en 13 de las mismas se confirma la relación entre exportaciones y crecimiento del producto.

En el ámbito nacional se han realizado trabajos donde, en general, se incorpora en una función típica de producción las exportaciones como variable proxy. Las exportaciones tienden a aumentar la productividad total de los factores. En esta línea se enmarcan los trabajos realizados por el Grupo de Estudios sobre Crecimiento Económico GRECO (Banco de la República [GRECO], 2002), Alonso y Patiño (2007), estos últimos no encontraron evidencia empírica en favor del crecimiento liderado por exportaciones. Recientemente, Cáceres (2013), utilizando datos trimestrales para Colombia, verificó la relación entre exportaciones y crecimiento del producto, pero no halló evidencia contundente respecto a que el PIB sea impulsado por las exportaciones; es decir, no encontró una relación de causalidad entre las exportaciones primarias e industriales y el producto neto de exportaciones. No obstante, añade que las divisas originadas por exportaciones han permitido la financiación de bienes de capital que han posibilitado ampliar el producto. 
DINÁMICA DE LAS

EXPORTACIONES Y EL

CRECIMIENTO

\section{ECONÓMICO EN BOYACÁ}

\section{Exportaciones y crecimiento económico en Boyacá 1980-2015}

Para el período comprendido entre 1980 y 2015; es decir, en los últimos 35 años, el crecimiento promedio del producto interno bruto del departamento de Boyacá fue apenas del 2,6\%, cifra inferior al crecimiento nacional, que fue del 3,6 $\%$. Por su parte, la tasa de crecimiento promedio de las exportaciones para el mismo período se ubicó en un $35 \%$, cifra global que indica intuitivamente que el sector exportador ha tenido un mejor desempeño y que, por tanto, ha respondido mejor a las exigencias de una economía más expuesta al comercio exterior (Tabla 1).

Tabla 1. Evolución del PIB y las exportaciones, Boyacá 1980-2015

\begin{tabular}{|c|c|c|}
\hline Años & Crecimiento promedio del PIB & $\begin{array}{c}\text { Crecimiento promedio de las } \\
\text { exportaciones }\end{array}$ \\
\hline $1980-1990$ & 1,9 & 70 \\
\hline $1991-2001$ & 1,1 & 30 \\
\hline $2002-2015$ & 4,5 & 15 \\
\hline $1980-2015$ & $\mathbf{2 , 6}$ & $\mathbf{3 5}$ \\
\hline
\end{tabular}

Fuente: elaboración propia con datos del DANE (2017).

En general, se observa un repunte importante de la economía boyacense, especialmente desde la década del 2000 , con un crecimiento promedio para dicho período del 4,5\%. Paralelamente, el sector exportador ha venido presentado una disminución secular en su dinámica de crecimiento, que pasó de un $70 \%$ en promedio para la década de los ochenta a tan solo un $15 \%$ para lo corrido del siglo XXI. El departamento de Boyacá en 1980 exportó, en términos reales (pesos de 2005), casi 32 millones de pesos, frente a 1,2 billones para el año 2015 (Figura 1). Esto indica que el sector exportador participaba en 1980 con tanto solo un $0,0005 \%$ del producto, frente a un $8,9 \%$ del PIB departamental para el año 2015. 


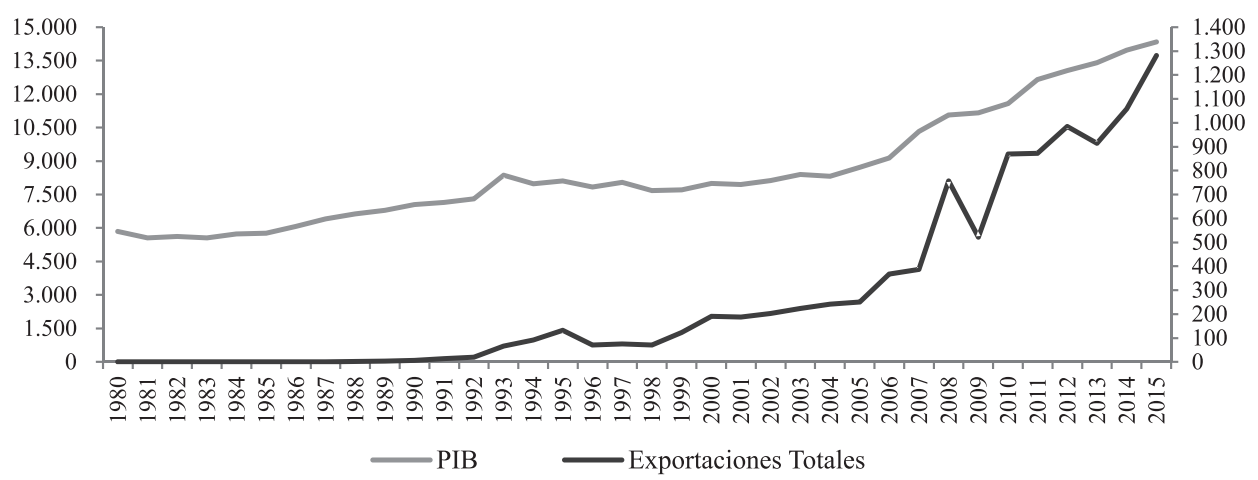

Figura 1. Evolución del PIB y las exportaciones (miles de millones de pesos de 2005), Boyacá 1980-2015.

Fuente: elaboración propia con datos del DANE (2017).

Sin embargo, a efectos del análisis conviene desagregar el período por décadas con el objeto de poder destacar ciertas características asociadas a la producción departamental. Se analiza la estructura económica del departamento de Boyacá, desde la perspectiva de los sectores productivos desarrollada por Fourastié.

Pero la intensidad del progreso está muy lejos de ser la misma en todas las ramas de la producción, y este carácter de irregularidad domina, a mi entender, la economía contemporánea. Impone, en efecto, la división de la economía en sectores profundamente distintos, según la intensidad del progreso técnico de que ha podido y pueden beneficiarse. Llamaré primarias a las actividades de progreso técnico medio (agrícolas), secundarias a las actividades de progreso técnico considerable (en general, industriales), y terciarias a las actividades de progreso técnico débil (comercio, administración, profesiones liberales, servicios personales, etc.). (Fourastié, 1956, pp. 22-23)

En los años ochenta, la economía nacional apenas se estaba alistando para la implementación de reformas económicas tendientes a competir en los escenarios mundiales. De tal suerte que las políticas vigentes obedecían al ya agotado modelo de sustitución de importaciones, donde el papel del Estado y su influencia en el desarrollo de la industria no surtieron los efectos esperados, y en el caso de la economía boyacense su producto solo creció un $1,9 \%$. Cabe resaltar el creciente aporte del sector primario al producto departamental, el cual pasó de un $26 \%$ en 1980 a un $35 \%$ en 1990 . El sector industrial, por su parte, se ubicó por debajo, tanto del sector terciario como del primario en su participación 
en el producto, pasando de un $24 \%$ en 1980 a un $17 \%$ en 1990 (Figura 2). Aquí ya es evidente el proceso de desindustrialización de la estructura productiva que desde los ochenta ha venido presentando el departamento, incluso hasta nuestros días, y que coincide con el proceso de desindustrialización en el ámbito nacional.

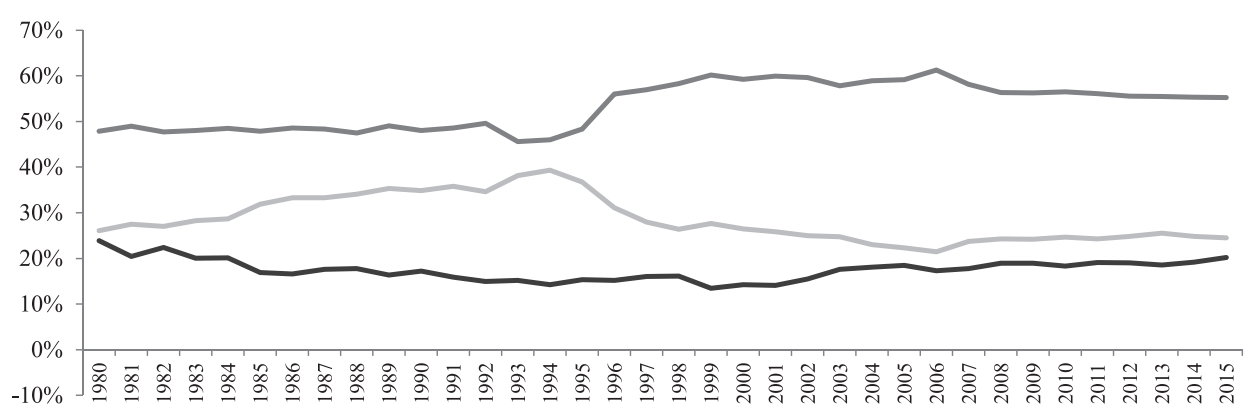

Sector Primario $\longrightarrow$ Sector Secundario $\longrightarrow$ Sector Terciario

Figura 2. Evolución porcentual de la participación sectorial en el PIB.

Boyacá 1980-2015. (Precios constantes de 2005).

Fuente: elaboración propia con datos del DANE (2017).

Para la década de los noventa se observa que el producto departamental disminuyó en 0,8 puntos porcentuales con respecto a la década de los ochenta, registrando un crecimiento promedio de tan solo un $1.1 \%$. El pobre desempeño obedece a los efectos adversos que tuvo la apertura económica para el sector primario, especialmente en la agricultura con la reducción de miles de hectáreas dedicadas a los cultivos transitorios (trigo, cebada y maíz, principalmente), ya que muchos de ellos fueron reemplazados por importaciones. Llama la atención la alta participación del sector terciario en el PIB, que para los ochenta representaba un $48 \%$ de la producción y desde los noventa dicho aporte se elevó a un $55 \%$. Entre las actividades que más se destacan están comercio, restaurantes, hoteles, servicios personales y actividades financieras.

La economía del departamento se ha terciarizado con servicios de poco valor agregado. Igualmente se evidencia la reducción paulatina de la producción agrícola en el producto, que como se observa en la Figura 2, pasó de un $38 \%$ en 1993 a un $25 \%$ en el año 2015. Situación similar afronta el sector secundario, pues la industria en los años noventa perdió su dinamismo y evidenció problemas estructurales de competitividad y eficiencia (en los no- 
venta solo aportaba el $15 \%$ del PIB). Las políticas de reconversión industrial y modernización, especialmente con una de las mayores empresas del departamento, Acerías Paz del Río, permitieron que dicha participación se incrementara al $18 \%$ del producto.

\section{Composición y dinámica de las exportaciones de Boyacá}

Las exportaciones totales para el período de estudio (1980-2015) registraron un crecimiento promedio del
$35 \%$ (Tabla 1 y Figura 3), cifra apreciable si se compara con el crecimiento promedio del producto departamental. Revisando el período en su conjunto se destaca el espectacular crecimiento de las ventas externas en la década de los ochenta con un no despreciable $70 \%$. Sin embargo, cuando se desagregan las exportaciones se evidencia que en más de un $96 \%$ la participación corresponde solo a un producto, esmeraldas. Esto significa que para la década de los ochenta, Boyacá era un departamento monoexportador.

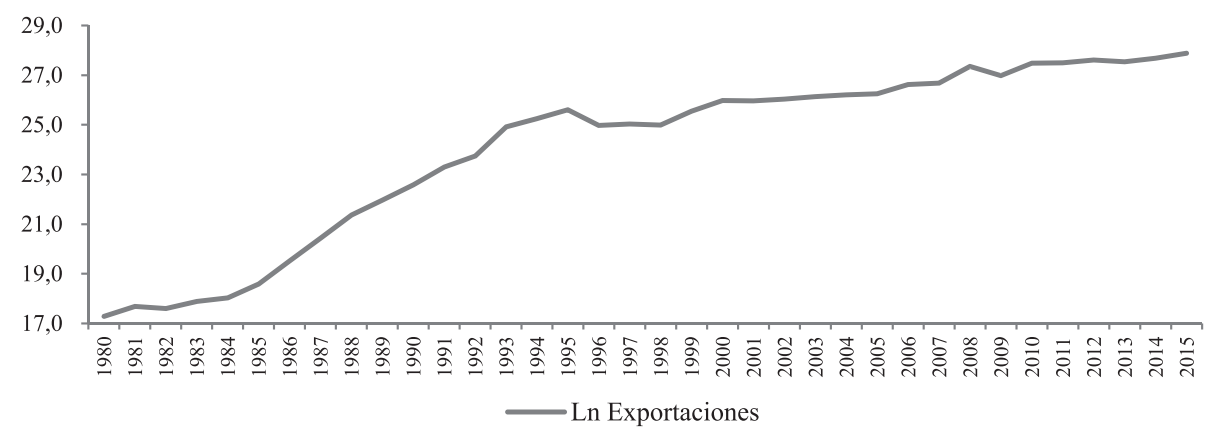

Figura 3. Evolución de las exportaciones (en logaritmo) Boyacá 1980-2015.

(Precios constantes de 2005).

Fuente: elaboración propia con datos del DANE (2017).

Paradójicamente, después de la puesta en marcha del proceso de apertura económica, el crecimiento promedio se redujo significativamente; en los noventa fue del $30 \%$, pese a que Boyacá comienza a exportar carbón coque y papa. La disminución de las exportaciones de esmeraldas repercutió en un menor ritmo de crecimiento del sector exportador. Esta misma tendencia se evidencia para la década del 2000 (hasta el año 2015), ya que el crecimiento fue tan solo del $15 \%$, situación agravada, además, por la reducción de las ventas de papa a Venezuela.

A continuación se desagregan las exportaciones con el objeto de identificar su composición y principales rubros de exportación. 
Apuntes CENES Volumen 37, Número 65

enero - junio 2018. Págs. 175-211

Tabla 2. Indicadores del sector externo. Boyacá 1980-2015

\begin{tabular}{|c|c|c|c|c|c|c|c|c|c|c|c|c|c|}
\hline \multicolumn{14}{|c|}{ (Porcentajes) } \\
\hline \multicolumn{14}{|c|}{ (Series a precios constantes de 2005) } \\
\hline & X/PIB & $X A / X$ & $\mathrm{XM} / \mathrm{X}$ & $\mathrm{XP} / \mathrm{X}$ & $\mathrm{XI} / \mathrm{X}$ & IAE & & $\begin{array}{c}X / \\
\text { PIB }\end{array}$ & $X A / X$ & $\underset{\mathrm{XM} /}{\mathrm{X}}$ & $\mathrm{XP} / \mathrm{X}$ & $\mathrm{XI} / \mathrm{X}$ & IAE \\
\hline & (1) & (2) & (3) & (4) & (5) & (6) & & (1) & (2) & (3) & (4) & (5) & (6) \\
\hline 1980 & $0,0005 \%$ & $0,10 \%$ & $96 \%$ & $96 \%$ & $3,5 \%$ & $0,001 \%$ & 1998 & $0,9 \%$ & $0,87 \%$ & $98 \%$ & $99 \%$ & $0,8 \%$ & $2 \%$ \\
\hline 1981 & $0,0009 \%$ & $0,00 \%$ & $95 \%$ & $95 \%$ & $4,6 \%$ & $0,001 \%$ & 1999 & $2 \%$ & $3,68 \%$ & $95 \%$ & $98 \%$ & $1,4 \%$ & $2 \%$ \\
\hline 1982 & $0,0008 \%$ & $0,21 \%$ & $94 \%$ & $94 \%$ & $4,7 \%$ & $0,001 \%$ & 2000 & $2 \%$ & $11,07 \%$ & $87 \%$ & $98 \%$ & $1,9 \%$ & $3 \%$ \\
\hline 1983 & $0,0011 \%$ & $0,00 \%$ & $94 \%$ & $94 \%$ & $6,1 \%$ & $0,001 \%$ & 2001 & $2 \%$ & $5,22 \%$ & $93 \%$ & $98 \%$ & $1,4 \%$ & $3 \%$ \\
\hline 1984 & $0,0012 \%$ & $0,10 \%$ & $94 \%$ & $94 \%$ & $6,3 \%$ & $0,001 \%$ & 2002 & $2 \%$ & $4,41 \%$ & $95 \%$ & $99 \%$ & $0,9 \%$ & $3 \%$ \\
\hline 1985 & $0,002 \%$ & $0,10 \%$ & $96 \%$ & $96 \%$ & $3,2 \%$ & $0,003 \%$ & 2003 & $3 \%$ & $2,69 \%$ & $96 \%$ & $99 \%$ & $0,8 \%$ & $4 \%$ \\
\hline 1986 & $0,005 \%$ & $0,00 \%$ & $96 \%$ & $96 \%$ & $3,8 \%$ & $0,005 \%$ & 2004 & $3 \%$ & $3,37 \%$ & $95 \%$ & $98 \%$ & $1,8 \%$ & $3 \%$ \\
\hline 1987 & $0,01 \%$ & $0,21 \%$ & $97 \%$ & $97 \%$ & $3,2 \%$ & $0,01 \%$ & 2005 & $3 \%$ & $5,37 \%$ & $92 \%$ & $98 \%$ & $1,9 \%$ & $4 \%$ \\
\hline 1988 & $0,03 \%$ & $0,13 \%$ & $90 \%$ & $90 \%$ & $9,6 \%$ & $0,03 \%$ & 2006 & $4 \%$ & $4,64 \%$ & $93 \%$ & $98 \%$ & $1,7 \%$ & $6 \%$ \\
\hline 1989 & $0,1 \%$ & $0,08 \%$ & $96 \%$ & $96 \%$ & $3,5 \%$ & $0,05 \%$ & 2007 & $4 \%$ & $0,10 \%$ & $98 \%$ & $99 \%$ & $1,2 \%$ & $7 \%$ \\
\hline 1990 & $0,1 \%$ & $0,77 \%$ & $93 \%$ & $94 \%$ & $5,8 \%$ & $0,1 \%$ & 2008 & $7 \%$ & $0,01 \%$ & $97 \%$ & $97 \%$ & $2,9 \%$ & $10 \%$ \\
\hline 1991 & $0,2 \%$ & $0,12 \%$ & $87 \%$ & $87 \%$ & $12,9 \%$ & $0,2 \%$ & 2009 & $5 \%$ & $0,02 \%$ & $97 \%$ & $97 \%$ & $3,2 \%$ & $7 \%$ \\
\hline 1992 & $0,3 \%$ & $1,59 \%$ & $95 \%$ & $96 \%$ & $3,5 \%$ & $0,3 \%$ & 2010 & $8 \%$ & $0,00 \%$ & $99 \%$ & $99 \%$ & $1,1 \%$ & $11 \%$ \\
\hline 1993 & $0,8 \%$ & $1,19 \%$ & $99 \%$ & $100 \%$ & $0,1 \%$ & $0,8 \%$ & 2011 & $7 \%$ & $0,67 \%$ & $98 \%$ & $99 \%$ & $1,1 \%$ & $11 \%$ \\
\hline 1994 & $1,2 \%$ & $1,38 \%$ & $98 \%$ & $100 \%$ & $0,3 \%$ & $1 \%$ & 2012 & $8 \%$ & $0,01 \%$ & $99 \%$ & $99 \%$ & $1,0 \%$ & $12 \%$ \\
\hline 1995 & $1,6 \%$ & $0,48 \%$ & $97 \%$ & $98 \%$ & $2,3 \%$ & $2 \%$ & 2013 & $7 \%$ & $2,06 \%$ & $97 \%$ & $99 \%$ & $0,5 \%$ & $9 \%$ \\
\hline 1996 & $0,9 \%$ & $0,05 \%$ & $100 \%$ & $100 \%$ & $0,2 \%$ & $1 \%$ & 2014 & $8 \%$ & $2,86 \%$ & $96 \%$ & $99 \%$ & $0,9 \%$ & $11 \%$ \\
\hline 1997 & $0,9 \%$ & $0,39 \%$ & $99 \%$ & $100 \%$ & $0,2 \%$ & $2 \%$ & 2015 & $9 \%$ & $2,43 \%$ & $97 \%$ & $99 \%$ & $0,5 \%$ & $12 \%$ \\
\hline sobr & total & U & 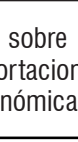 & $p$ & . & . & . & r & one & ( & 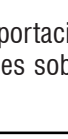 & la & Ilas \\
\hline
\end{tabular}

Fuente: elaboración propia con datos del DANE (2017).

La participación de las exportaciones del departamento de Boyacá dentro de su producto interno bruto se caracteriza por ser relativamente baja y poco diversificada (Tabla 2). Para la década de los ochenta representaba solo un $0,02 \%$ de la producción, lo cual indica que el departamento tenía poca vocación exportadora. Sin embargo se han hecho esfuerzos por parte de la administración pública y privada boyacense con el fin de ampliar tanto la oferta exportable como su participación relativa, de tal manera que a partir de los 
años noventa dicha participación se ha venido elevando, representando en la actualidad el $9 \%$ de la producción departamental.

La oferta exportable de Boyacá proviene básicamente del sector primario, en 1980 representaba el $96 \%$, que corresponde a bienes mineros, especialmente esmeraldas y carbón coque. Dicha situación no ha cambiado con el paso del tiempo, incluso se ha incrementado al $99 \%$ para el año 2015. Igualmente, la Tabla 2 muestra que el índice de apertura económica (importaciones más exportaciones sobre PIB) del departamento de Boyacá es muy bajo ( $2 \%$ en 1980 y $12 \%$ en 2015), lo que revela que es un departamento poco abierto al comercio. Por su parte, la participación de las exportaciones industriales hoy es más baja que hace 30 años. Para los ochenta representaba, en promedio, un $5 \%$ de las exportaciones totales, en los últimos años (en lo corrido de este siglo) participan con un $1,4 \%$.

\section{Composición y dinámica de las ex- portaciones primarias de Boyacá}

Boyacá se caracteriza por tener una oferta exportable con bajo valor agregado y poco diversificada. De hecho, los bienes exportables más representativos proceden del sector minero; esto es, carbón y esmeraldas. Las ventas externas de dichos bienes representaron en 1980 el $96 \%$ de las exportaciones totales y para 2015 su participación se incrementó al 97 \% (Figura 4).

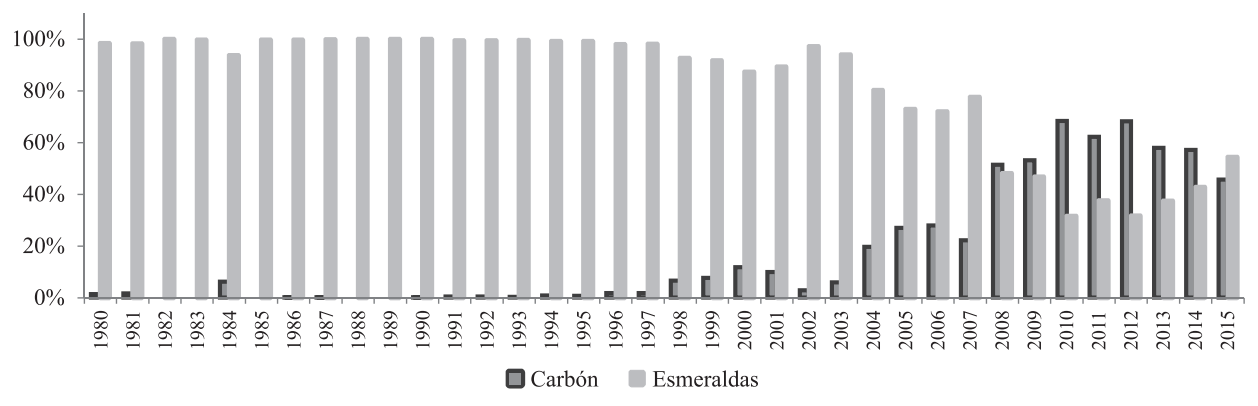

Figura 4. Evolución porcentual y participación de los principales productos mineros. Boyacá 1980 -2015. (Precios constantes de 2005).

Fuente: elaboración propia con datos del DANE (2017).

Boyacá es el departamento con los mayores yacimientos de esmeraldas de Colombia, ubicados en los municipios de Muzo, Coscuez y
Chivor. Con la llegada de los conquistadores españoles en el siglo $\mathrm{XVI}$, los nativos fueron despojados de las minas y su explotación pasó 
a la Corona española. Ya desde esa época las esmeraldas se enviaban hacia Europa y Asia.

Hasta 1567, las esmeraldas que se enviaban a España desde el Nuevo Mundo eran, en su mayoría, tomadas a la fuerza; únicamente pequeñas cantidades eran extraídas de las minas de Somondoco. El capitán Benito de Poveda dio comienzo a la primera explotación minera en Muzo utilizando más soldados e indígenas para proteger la mina que excavadores propiamente dichos. El esfuerzo fue fructífero y se recogieron muchos cristales de esmeralda finos y claros, la mayoría de los cuales eran considerados tan valiosos que debían ser enviados a la corte real en Madrid. (Ringsrud, 2013, p. 43)

Durante las décadas de los ochenta y noventa las exportaciones de esmeraldas representaban más del $98 \%$ de las exportaciones del departamento; sin embargo, la disminución en la producción (volumen) desde el año 2002 se ha visto reflejada en una menor participación en el valor exportado, en la actualidad este rubro representa el $59 \%$ de la oferta exportable. A mediados de los noventa hace su aparición el carbón como mineral comercializable internacionalmente. En los noventa contribuía con un $3 \%$ de las ventas totales y para lo corrido del siglo XXI participa, en promedio, con el $39 \%$ del comercio exterior de bienes. Si bien estos productos contribuyen con el crecimiento económico, no se aprecia una mejora en los niveles de ingreso y bienestar en la población de los municipios de influencia, entre otras razones porque son actividades que generan poco empleo, de baja calificación y remuneración de la mano de obra local. Además, los recursos por regalías son ínfimos comparados con el valor de dichas exportaciones.

Por su parte, la contribución del sector agrícola en las exportaciones totales es relativamente marginal:

[...] el departamento de Boyacá no dispone de una producción agraria que facilite la explotación de cultivos comerciales que hagan ventajosas las economías de escala a través de corrientes de tecnología agrícola de avanzada, productividad creciente y mayor competitividad en los mercados de origen interno y externo. No existe, entonces, una agricultura de tipo FARMER como la de E.U., de grandes extensiones y rendimientos aceptables, con bajos costos de producción por hectárea y uso racional de los factores como el capital y el trabajo. (Arévalo, 2004, p.192-193)

En 1980 representaban un $0,1 \%$ de las exportaciones boyacenses, para el año 2015 su participación se elevó a un $2,43 \%$, contribución relativamente pequeña si se tiene en cuenta el período de estudio. Los bienes más representativos del sector son la papa y las flores (Figura 5). 


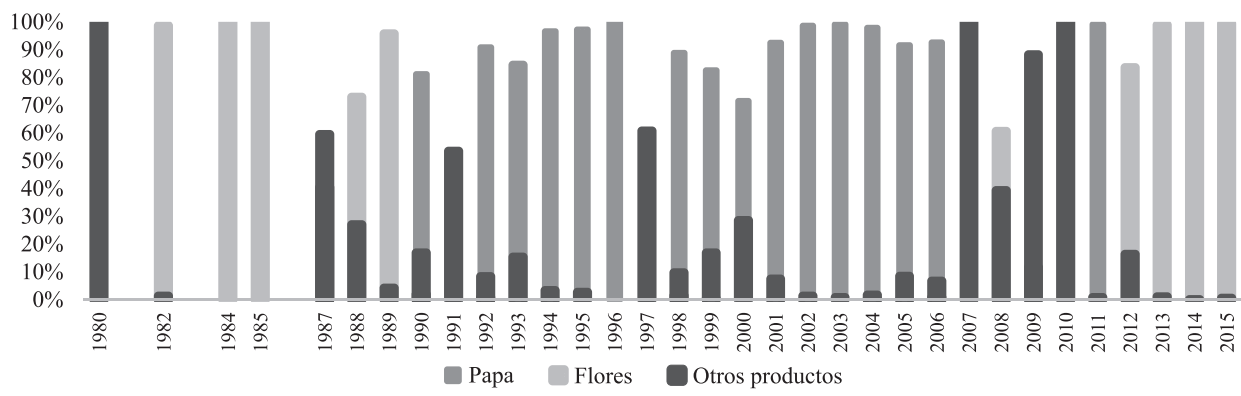

Figura 5. Evolución porcentual y participación de los principales productos agrícolas. Boyacá 1980-2015. (Precios constantes de 2005).

Fuente: elaboración propia con datos del DANE (2017).

Para la década de los noventa, el $80 \%$ de las exportaciones del sector agrícola correspondía a venta de papa, representando importantes ingresos para los productores locales. Por ejemplo, en 1990 se exportó a Venezuela un valor de 40 millones de pesos, ya para el 2006 esta cifra ascendió a 15.700 millones de pesos. Con la creación de una zona de libre comercio en 1991, el comercio bilateral entre Colombia y Venezuela se incrementó.

La rebaja de aranceles frente a terceros fue sustancial tanto de Colombia como de Venezuela (en Colombia ocurrió a comienzos de los noventa y en Venezuela a fines de los ochenta), pero de todas maneras se mantuvieron ventajas para el comercio bilateral, con aranceles de cero, mientras que los niveles frente a otros países fueron superiores (en promedio 11\%). Es decir, se mantuvo algún incentivo al intercambio intrarregional y para el desarrollo de la complementación industrial, pero se redujeron sustancialmente sus ventajas. (Esguerra, Montes, Garavito \& Pulido, 2010, p.5)

Las anteriores medidas se evidenciaron en el crecimiento de las exportaciones de papa hasta el año 2006. No obstante, la firma por parte de Colombia del TLC con Estados Unidos no fue bien vista por el vecino país, y la salida de Venezuela de la Comunidad Andina de Naciones CAN generó medidas restrictivas relacionadas con la demora en los pagos a los exportadores colombianos y la no renovación de permisos sanitarios. Los anteriores hechos, junto con la reducción en el crecimiento económico en Venezuela, impactaron negativamente las ventas de papa hacia dicho país. Desde entonces, excepto el año 2011, no se han hecho exportaciones del producto al país vecino.

Las exportaciones de flores han sido intermitentes, tal como se observa en 
la Figura 5, en la década de los noventa no se hizo ninguna exportación del producto y solo hasta el 2008 se reactivaron nuevamente. Este rubro contribuye, en promedio (para lo corrido del período 2008-2015), con el $57 \%$ de las exportaciones agrícolas.

Las exportaciones agroindustriales ocupan un lugar marginal en la oferta exportadora del departamento de Boyacá, su participación en las expor- taciones totales es muy pequeña, en promedio representan el 0,11\%. Aquí se destacan los rubros de azúcares y artículos de confitería, especialmente la preparación de jarabes y dulces. En el rubro de preparación de hortalizas están las compotas, los jugos y purés (Figura 6). Los anteriores datos reflejan el poco valor agregado que se le añade a los productos agroindustriales que utilizan materias primas del sector agrícola.

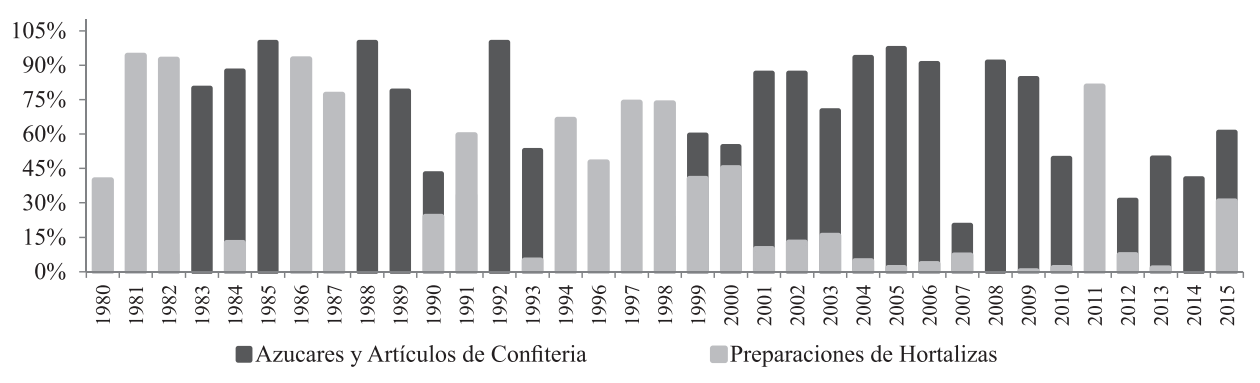

Figura 6. Evolución porcentual y participación de los principales productos agroindustriales. Boyacá 1980-2015. (Precios constantes de 2005).

Fuente: elaboración propia con datos del DANE (2017).

\section{Composición y dinámica de las exportaciones industriales de Boyacá}

La producción industrial con destino a los mercados internacionales del departamento de Boyacá es relativamente baja. Su participación en 1980 era del 3,5\%, que si bien no era muy alta, se veía beneficiada por las medidas proteccionistas aplicadas por el Gobierno para favorecer la industria nacional y local. Sin embargo, para el año 2015, la participación del sector industrial en las exportaciones totales solo representa un 0,5\% (ver Tabla 2). El cambio de modelo económico expuso la industria a la competencia internacional evidenciando problemas estructurales de eficiencia y competitividad. Este es el caso de la siderurgia y la industria del hierro y el acero (ubicada en Belencito, Boyacá). 


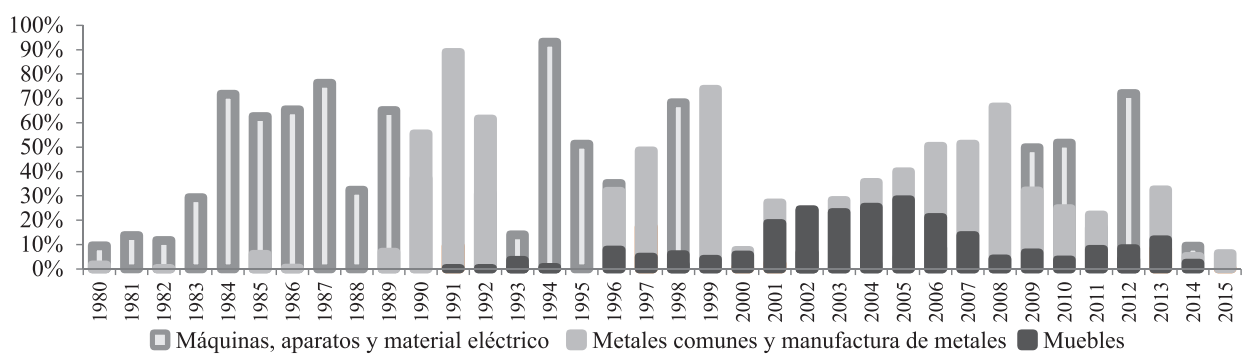

Figura 7. Evolución porcentual y participación de los principales productos industriales. Boyacá 1980-2015. (Precios constantes de 2005).

Fuente: elaboración propia con datos del DANE (2017).

Dentro de los rubros más destacados de la industria exportadora se destacan, en los años ochenta, la fabricación de máquinas, aparatos y material eléctrico; especialmente la fabricación de motores para automóviles, en cabeza de la desaparecida Sociedad de Fabricación de Automotores S.A. SOFASA, empresa emblemática del corredor industrial de Boyacá (ubicada en la ciudad de Duitama) que llegó a generar más de 1000 empleos en la región.

Después de la venta de la empresa en los años noventa, prácticamente desaparecieron las exportaciones de este sector (Figura 7).

Sin embargo, la siderurgia tiene una presencia importante en el departamento y parte de su producción se exporta con productos derivados del hierro y el acero. Igualmente, se destaca la fabricación y exportación de muebles de madera.

\section{LOS VÍNCULOS ENTRE EX- PORTACIONES Y CRECI- MIENTO EN BOYACÁ}

\section{Datos y especificación del modelo}

En la literatura internacional, la relación entre crecimiento y exportaciones es conocida bajo la hipótesis de "export led growth"; es decir, crecimiento impulsado por las exportaciones. La mayoría de las investigaciones sobre los vínculos entre las exportaciones y el crecimiento económico utilizan funciones de producción ampliadas, las cuales incorporan, además de las variables típicas (capital y trabajo), las exportaciones, y la razón es porque estas últimas contribuyen con el crecimiento económico a través del incremento en la productividad total de los factores. El modelo adaptado por Cáceres (2013) proviene de Siliverstovs y Herzer (2006), aplicado para testear la relación entre exportaciones y crecimiento en Chile. Se parte de una 
función de producción neoclásica con las siguientes características:

$$
N Y_{t}=A_{t} K_{t}^{\alpha} L_{t}^{\beta}
$$

Donde $N Y_{t}$ corresponde a la producción agregada departamental descontadas las exportaciones. Como estas están contabilizadas dentro de la identidad del ingreso nacional, es necesario restarlas precisamente para ver sus efectos sobre el producto; $K_{t}$ es la inversión neta; $L_{t}$ es la fuerza laboral medida por el personal ocupado en la industria manufacturera $\mathrm{y}$, finalmente $A_{t}$ es la productividad total de los factores. Todas las variables están indexadas. Se entiende que la productividad total de los factores está determinada de manera lineal-logarítmica por el nivel de exportaciones primarias $X P_{t}$, las exportaciones manufactureras $X I_{t} \mathrm{y}$ otros factores exógenos resumidos en la variable $C_{t}$ :

$$
\mathrm{A}_{\mathrm{t}}=\mathrm{XP}_{\mathrm{t}}^{\gamma} \mathrm{XI}_{\mathrm{t}}{ }^{\rho} \mathrm{C}_{\mathrm{t}}
$$

Sustituyendo (2) en (1), tenemos:

$$
N Y_{t}=C_{t} K_{t}^{\alpha} L_{t}^{\beta} X P_{t}^{\gamma} X I_{t}^{\rho}
$$

Tomando en ambos lados de la ecuación (3) logaritmos naturales y agregando el término de error resulta la siguiente función lineal:

$$
\begin{gathered}
\ln N Y_{t}= \\
C+\alpha \ln K_{t}+\beta \operatorname{Ln} L_{t}+\gamma \ln X P_{t}+\rho \ln X I_{t}+e_{t}
\end{gathered}
$$

[4]

En general, la ecuación (4) indica el equilibrio a largo plazo entre las exportaciones descontadas del PIB departamental y las diferentes variables independientes. Las series empleadas corresponden a datos anuales para el departamento de Boyacá de 1980 al 2015 (Anexo 1). Las series son el PIB neto de exportaciones $\mathrm{NY}_{\mathrm{t}}$, serie deflactada por la metodología de encadenamiento a precios constantes del año 2005; para la variable capital $\mathrm{K}_{t}$, se tomó como variable "proxy" la inversión neta a precios constantes de 2005 utilizando el deflactor implícito del PIB. Es de anotar que no se encontraron datos para el período 1996-2005, en cuyo caso se procedió a proyectar la serie para dicho período; el personal ocupado en la industria manufacturera $\mathrm{L}_{\mathrm{t}}$; las exportaciones primarias $\mathrm{XP}_{\mathrm{t}}$ y las exportaciones industriales $\mathrm{KI}_{\mathrm{t}}$. Estas dos últimas llevadas a pesos constantes (utilizando el deflactor del PIB neto $(2005=1)$. La información se tomó del Departamento Administrativo Nacional de Estadística DANE (2016).

\section{Orden de integración y pruebas de estacionariedad}

Se determinará si las series son estacionarias, en caso de no serlo se buscará 
establecer el orden de integración. De esta manera, se procede a realizar en

$\log$ KT

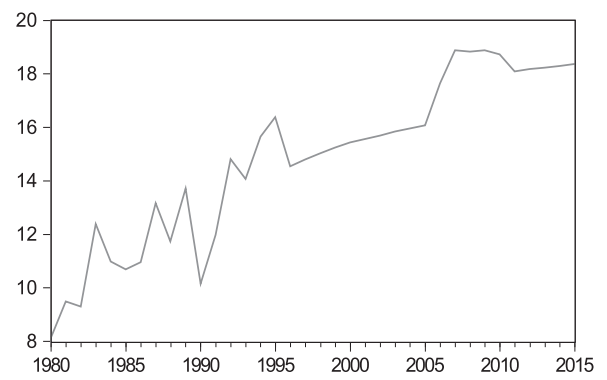

Log PIBNT

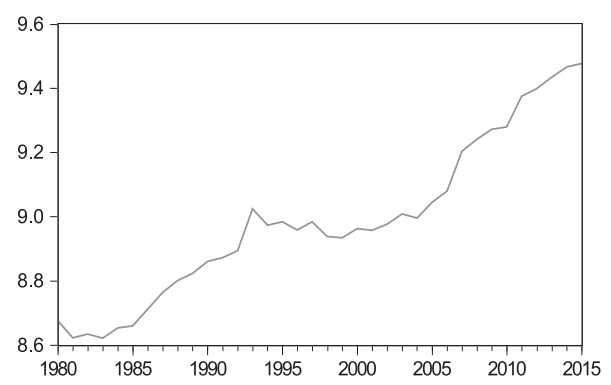

$\log$ XPT

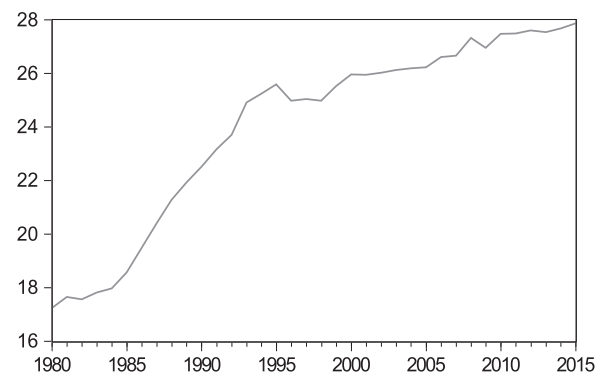

primer lugar el análisis gráfico de cada una de las series por estudiar.

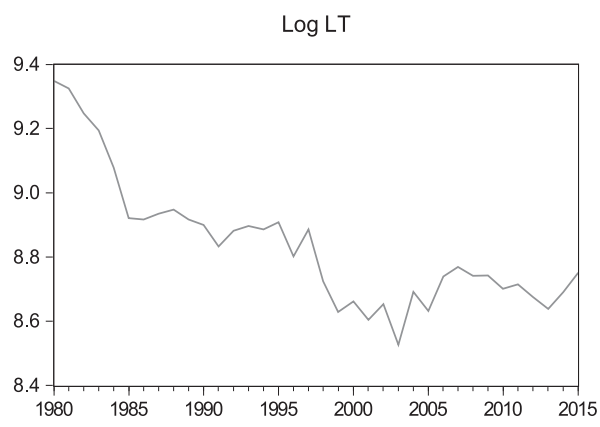

$\log$ XIT

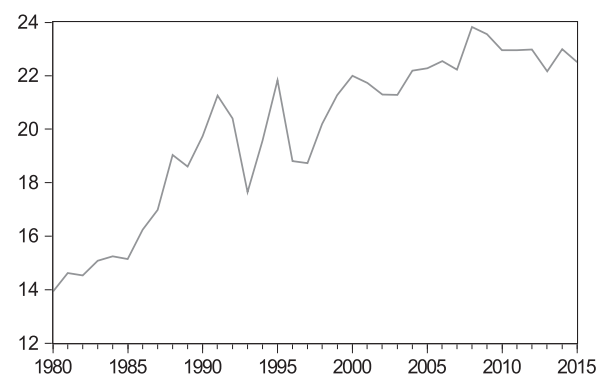

Figura 8. Análisis gráfico de las series.

Fuente: elaboración propia con datos del DANE (2017).

Se aprecia que las series tienen una tendencia determinística, lo cual hace suponer que no poseen media constante en el tiempo; es decir, que no son estacionarias. Sin embargo, se procede en la aplicación de pruebas 
más formales y precisas que permitan establecer la estacionariedad de las series. El análisis de estacionariedad se lleva a cabo a través de las pruebas
Dickey Fuller aumentada (Dickey \& Fuller, 1979) y Phillips Perron (Phi1lips \& Perron, 1988). A continuación se presentan los resultados obtenidos.

Tabla 3. Análisis de estacionariedad

\begin{tabular}{|c|c|c|c|c|}
\hline & \multicolumn{2}{|c|}{ Nivel } & \multicolumn{2}{c|}{ Primera diferencia } \\
\hline & ADF & PP & ADF & PP \\
\hline Kt & -1.979056 & -1.947475 & $-3.930129^{\star *}$ & $-11.40504^{\star *}$ \\
\hline & $(0.2943)$ & $(0.3077)$ & $(0.0051)$ & $(0.0000)$ \\
\hline Lt & -2.144157 & -2.039261 & $-7.822951^{\star *}$ & $-7.822951^{\star *}$ \\
\hline & $(0.5039)$ & $(0.5603)$ & $(0.0000)$ & $(0.0000)$ \\
\hline PIBNt & 0.812437 & 0.912273 & $-6.378632^{\star *}$ & $-6.340152^{\star *}$ \\
\hline & $(0.9929)$ & $(0.9945)$ & $(0.0000)$ & $(0.0000)$ \\
\hline XIt & -2.25028 & -2.159957 & $-7.205651^{* *}$ & $-7.751982^{\star *}$ \\
\hline & $(0.1934)$ & $(0.2238)$ & $(0.0000)$ & $(0.0000)$ \\
\hline XPt & -0.664162 & -0.664162 & $-3.866008^{\star *}$ & $-4.64313^{* *}$ \\
\hline & $(0.9681)$ & $(0.9681)$ & $(0.0256)$ & $(0.0038)$ \\
\hline
\end{tabular}

**Indica que se rechaza la hipótesis nula al $5 \%$ de significancia.

Entre paréntesis se encuentran los p-valores asociados a cada prueba.

Se evidencia que las pruebas ADF y PP tienen p-valores mayores a 0,05 cuando las series están en sus niveles; es decir, sin ninguna transformación. Por otro lado, al aplicar una diferencia regular, los p-valores son menores al nivel de significancia de $5 \%$. En consecuencia, se concluye que el orden de integración de todas las series analizadas es 1 . Por lo tanto, dado que todas las series son I (1) es posible determinar si existe una relación a largo plazo, para ello se hará un análisis de cointegración.

\section{Relación a largo plazo (cointegración)}

Para establecer si hay una relación a largo plazo entre las variables estudiadas, se procederá a realizar la prueba de cointegración de Johansen, (Johansen, 1988). A continuación se presentan los resultados de la prueba de la traza y de máximos valores propios para las series: 
Tabla 4. Resultados pruebas de cointegración

\begin{tabular}{|c|c|c|c|c|}
\hline \multicolumn{5}{|c|}{ Unrestricted Cointegration Rank Test (Trace) } \\
\hline $\begin{array}{l}\text { Hypothesized } \\
\text { No. of CE(s) }\end{array}$ & Eigenvalue & $\begin{array}{c}\text { Trace } \\
\text { Statistic }\end{array}$ & $\begin{array}{c}0.05 \\
\text { Critical Value }\end{array}$ & Prob.** \\
\hline None * & 0.708489 & 86.49898 & 69.81889 & 0.0013 \\
\hline At most 1 & 0.415078 & 44.58798 & 47.85613 & 0.0982 \\
\hline At most 2 & 0.375956 & 26.35460 & 29.79707 & 0.1184 \\
\hline At most 3 & 0.257891 & 10.32241 & 15.49471 & 0.2567 \\
\hline At most 4 & 0.005327 & 0.181596 & 3.841466 & 0.6700 \\
\hline \multicolumn{5}{|c|}{$\begin{array}{l}\text { Trace test indicates } 1 \text { cointegrating eqn(s) at the } 0.05 \text { level } \\
* \text { denotes rejection of the hypothesis at the } 0.05 \text { level } \\
\text { **MacKinnon-Haug-Michelis (1999) p-values } \\
\text { Unrestricted Cointegration Rank Test (Maximum Eigenvalue) }\end{array}$} \\
\hline $\begin{array}{l}\text { Hypothesized } \\
\text { No. of CE(s) }\end{array}$ & Eigenvalue & $\begin{array}{l}\text { Max-Eigen } \\
\text { Statistic }\end{array}$ & $\begin{array}{c}0.05 \\
\text { Critical Value }\end{array}$ & Prob.** \\
\hline None * & 0.708489 & 41.91100 & 33.87687 & 0.0045 \\
\hline At most 1 & 0.415078 & 18.23338 & 27.58434 & 0.4758 \\
\hline At most 2 & 0.375956 & 16.03219 & 21.13162 & 0.2230 \\
\hline At most 3 & 0.257891 & 10.14081 & 14.26460 & 0.2029 \\
\hline At most 4 & 0.005327 & 0.181596 & 3.841466 & 0.6700 \\
\hline \multicolumn{5}{|c|}{$\begin{array}{l}\text { Max-eigenvalue test indicates } 1 \text { cointegrating eqn(s) at the } 0.05 \text { level } \\
\text { * denotes rejection of the hypothesis at the } 0.05 \text { level } \\
\text { **MacKinnon-Haug-Michelis (1999) p-values }\end{array}$} \\
\hline
\end{tabular}

Se evidencia que tanto la prueba de la traza, como la de máximos valores propios, dan como resultado que existe una relación de cointegración a largo plazo entre las variables. De este modo es posible estimar un modelo VAR (p) con las variables en niveles cuya especificación es la siguiente (ecuación 5):

$$
\mathrm{X}_{\mathrm{t}}=\mathrm{A}+\mathrm{B}(\mathrm{L}) \mathrm{X}_{\mathrm{t}}+\varepsilon_{\mathrm{t}}
$$

donde $\varepsilon_{\mathrm{t}} \sim \mathrm{N}_{\mathrm{p}}(0, \Sigma)$ 
Donde $X_{t}$ es un vector con las variables de interés, A es un vector de constantes de tamaño $7 \mathrm{x} 1$; (L) es el polinomio operador de rezago y $\varepsilon_{\mathrm{t}}$ es un vector de errores no correlacionados que se distribuyen normal multivaria- dos con media cero y matriz de varianzas y covarianzas $\Sigma$. El modelo VAR que mejores resultados produce y que garantiza que sus errores sean ruido blanco es un VAR (2), los resultados son los siguientes:

Tabla 5. Resultados vector autorregresivo VAR

\begin{tabular}{|c|c|c|c|c|c|}
\hline \multicolumn{6}{|c|}{$\begin{array}{l}\text { Vector Autoregression Estimates } \\
\text { Date: 06/16/17 Time: 06:06 } \\
\text { Sample (adjusted): } 19822015 \\
\text { Included observations: } 34 \text { after adjustments } \\
\text { Standard errors in ( ) \& t-statistics in [ ] }\end{array}$} \\
\hline & LKT & LLT & LPIBNT & LXIT & LXPT \\
\hline \multirow{3}{*}{ LKT(-1) } & 0.232289 & 0.001683 & 0.011931 & -0.029721 & 0.009135 \\
\hline & $(0.20347)$ & $(0.01127)$ & $(0.00512)$ & $(0.17730)$ & $(0.06018)$ \\
\hline & [ 1.14165$]$ & [ 0.14931$]$ & [ 2.33092] & {$[-0.16763]$} & [ 0.15179$]$ \\
\hline \multirow{3}{*}{ LKT(-2) } & -0.016117 & -0.021079 & -0.000875 & 0.006198 & -0.072943 \\
\hline & $(0.21896)$ & $(0.01213)$ & $(0.00551)$ & $(0.19079)$ & $(0.06476)$ \\
\hline & {$[-0.07361]$} & {$[-1.73735]$} & {$[-0.15893]$} & [ 0.03249] & {$[-1.12631]$} \\
\hline \multirow{3}{*}{$\operatorname{LLT}(-1)$} & -0.669183 & 0.437699 & 0.054960 & -4.430682 & -1.615999 \\
\hline & (3.40282) & $(0.18856)$ & $(0.08560)$ & (2.96512) & (1.00648) \\
\hline & {$[-0.19666]$} & [ 2.32129] & [ 0.64202] & {$[-1.49427]$} & {$[-1.60559]$} \\
\hline \multirow{3}{*}{$\operatorname{LLT}(-2)$} & 0.777436 & 0.297939 & -0.176168 & 0.880742 & -0.027393 \\
\hline & (3.65309) & $(0.20243)$ & $(0.09190)$ & (3.18321) & (1.08051) \\
\hline & [ 0.21282$]$ & [ 1.47184] & {$[-1.91696]$} & [ 0.27668] & {$[-0.02535]$} \\
\hline \multirow{3}{*}{ LPIBNT(-1) } & 13.34057 & 0.067724 & 0.511443 & 8.770707 & 2.778587 \\
\hline & $(7.02505)$ & $(0.38927)$ & $(0.17673)$ & (6.12143) & (2.07786) \\
\hline & [1.89900] & [ 0.17397] & [ 2.89396] & [ 1.43279] & [ 1.33724] \\
\hline \multirow{3}{*}{ LPIBNT(-2) } & -10.84824 & 0.116329 & 0.519119 & -7.638887 & -2.216615 \\
\hline & $(7.17494)$ & $(0.39758)$ & $(0.18050)$ & (6.25205) & (2.12219) \\
\hline & {$[-1.51196]$} & [0.29259] & [ 2.87603] & {$[-1.22182]$} & {$[-1.04449]$} \\
\hline
\end{tabular}


Las exportaciones y el crecimiento económico en Boyacá Colombia 1980-2015

Willyam Cáceres-Rodríguez - Omaira Inés Agudelo-Cely - Ricardo Alonso Tejedor-Estupiñán

Continuación de la Tabla 5.

\begin{tabular}{|c|c|c|c|c|c|}
\hline \multirow{3}{*}{$\operatorname{LXIT}(-1)$} & 0.238781 & -0.009653 & 0.000829 & 0.474772 & -0.007250 \\
\hline & $(0.23707)$ & $(0.01314)$ & $(0.00596)$ & $(0.20658)$ & $(0.07012)$ \\
\hline & [ 1.00721$]$ & {$[-0.73478]$} & [ 0.13895] & [ 2.29828] & {$[-0.10340]$} \\
\hline \multirow{3}{*}{$\operatorname{LXIT(-2)~}$} & -0.263092 & 0.018416 & 0.022129 & -0.375853 & 0.056611 \\
\hline & $(0.24854)$ & $(0.01377)$ & $(0.00625)$ & $(0.21657)$ & $(0.07351)$ \\
\hline & {$[-1.05853]$} & [ 1.33715] & [ 3.53926] & {$[-1.73545]$} & [ 0.77008] \\
\hline \multirow{3}{*}{ LXPT(-1) } & -0.340771 & 0.032055 & 0.008225 & 0.464770 & 0.917283 \\
\hline & $(0.71968)$ & $(0.03988)$ & $(0.01810)$ & $(0.62711)$ & $(0.21286)$ \\
\hline & {$[-0.47351]$} & [ 0.80379] & [ 0.45430] & [ 0.74113] & [ 4.30922] \\
\hline \multirow{3}{*}{ LXPT(-2) } & 0.762564 & -0.037176 & -0.041876 & -0.014058 & -0.072491 \\
\hline & $(0.70651)$ & $(0.03915)$ & $(0.01777)$ & $(0.61564)$ & $(0.20897)$ \\
\hline & [1.07933] & {$[-0.94958]$} & {$[-2.35606]$} & {$[-0.02283]$} & {$[-0.34689]$} \\
\hline \multirow{3}{*}{$C$} & -21.22840 & 0.882717 & 1.015401 & 28.63815 & 13.37597 \\
\hline & (27.9108) & $(1.54660)$ & $(0.70215)$ & $(24.3207)$ & $(8.25542)$ \\
\hline & {$[-0.76058]$} & [ 0.57075] & [ 1.44614] & [1.17752] & [ 1.62027$]$ \\
\hline R-squared & 0.882677 & 0.892594 & 0.990133 & 0.904270 & 0.991988 \\
\hline Adj. R-squared & 0.831667 & 0.845896 & 0.985842 & 0.862648 & 0.988505 \\
\hline Sum sq. Resids & 30.76796 & 0.094474 & 0.019472 & 23.36181 & 2.691732 \\
\hline S.E. equation & 1.156606 & 0.064090 & 0.029096 & 1.007835 & 0.342099 \\
\hline F-statistic & 17.30395 & 19.11405 & 230.7916 & 21.72590 & 284.7871 \\
\hline Log likelihood & -46.54584 & 51.81457 & 78.66352 & -41.86453 & -5.128924 \\
\hline Akaike AIC & 3.385049 & -2.400857 & -3.980207 & 3.109678 & 0.948760 \\
\hline Schwarz SC & 3.878872 & -1.907034 & -3.486385 & 3.603501 & 1.442583 \\
\hline Mean dependent & 15.12166 & 8.806825 & 9.007666 & 20.28412 & 24.42182 \\
\hline S.D. dependent & 2.819033 & 0.163262 & 0.244538 & 2.719394 & 3.190817 \\
\hline \multicolumn{2}{|c|}{$\begin{array}{l}\text { Determinant resid covariance } \\
\text { (dof adj.) }\end{array}$} & $3.06 \mathrm{E}-07$ & & & \\
\hline \multicolumn{2}{|c|}{ Determinant resid covariance } & 4.34E-08 & & & \\
\hline \multicolumn{2}{|l|}{ Log likelihood } & 46.98007 & & & \\
\hline \multicolumn{2}{|c|}{ Akaike information criterion } & 0.471761 & & & \\
\hline \multicolumn{2}{|l|}{ Schwarz criterion } & 2.940873 & & & \\
\hline
\end{tabular}




\section{Causalidad en el sentido Granger}

El test más relevante en el presente estudio es el análisis de causalidad entre exportaciones y crecimiento económico. La prueba de causalidad vectorial de Granger (Granger, 1969) para el modelo que tiene como variable de- pendiente el logaritmo del PIB neto arroja que en conjunto las variables escogidas causan en el sentido Granger al PIB, especialmente las exportaciones industriales (LXIT) y las exportaciones primarias (LXPT), lo cual prueba la hipótesis de crecimiento fundamentado en exportaciones.

Tabla 6. Análisis de causalidad de Granger (LPIBNT)

\begin{tabular}{|c|c|c|c|}
\hline \multicolumn{5}{|l|}{ Dependent variable: LPIBNT } \\
\hline Excluded & Chi-sq & df & Prob. \\
\hline LKT & 5.617410 & 2 & 0.0603 \\
\hline LLT & 4.713335 & 2 & 0.0947 \\
\hline LXIT & 15.30848 & 2 & 0.0005 \\
\hline LXPT & 22.01430 & 2 & 0.0000 \\
\hline All & 33.28714 & $\mathbf{8}$ & $\mathbf{0 . 0 0 0 1}$ \\
\hline
\end{tabular}

De la misma manera, realizando la prueba de causalidad para el logaritmo de las exportaciones industriales (LXIT), se encontró que estas tam- bién son causadas de manera conjunta por los factores trabajo y capital, por el PIB neto y las exportaciones primarias.

Tabla 7. Análisis de causalidad de Granger (LXIT)

\begin{tabular}{|c|c|c|c|}
\hline \multicolumn{4}{|l|}{ Dependent variable: LXIT } \\
\hline Excluded & Chi-sq & df & Prob. \\
\hline LKT & 0.028185 & 2 & 0.9860 \\
\hline LLT & 3.469297 & 2 & 0.1765 \\
\hline LPIBNT & 2.156875 & 2 & 0.3401 \\
\hline LXPT & 2.998309 & 2 & 0.2233 \\
\hline All & 15.66527 & 8 & 0.0474 \\
\hline
\end{tabular}


Para las demás series no se encontraron relaciones de causalidad entre bloques de variables. Por ende, se omiten estos resultados.

\section{Función impulso respuesta}

En consecuencia y dado que las exportaciones causan en el sentido Granger

Response to Cholesky One S.D. Innovations \pm 2 S.E
Response of LPIBNT to LKT

Response of LPIBNT to LXIT

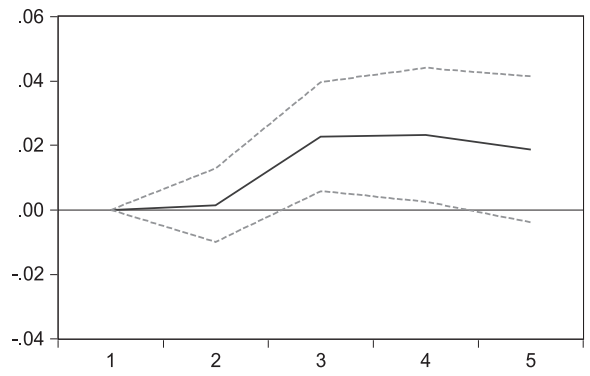

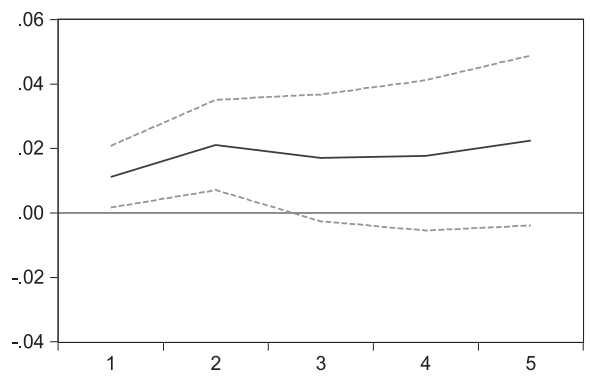

al PIB, se analizarán los impulsos respuesta que generan los dos tipos de exportaciones (industriales y primarias), el capital y el número de trabajadores sobre el producto interno bruto neto.
Figura 9. Análisis gráfico funciones impulso respuesta
Se aprecia que el PIB neto aumenta cuando se producen choques positivos sobre las exportaciones industriales con un rezago de tres periodos, este efecto se mantiene por un periodo más y se disipa en el quinto año,
Response of LPIBNT to LLT

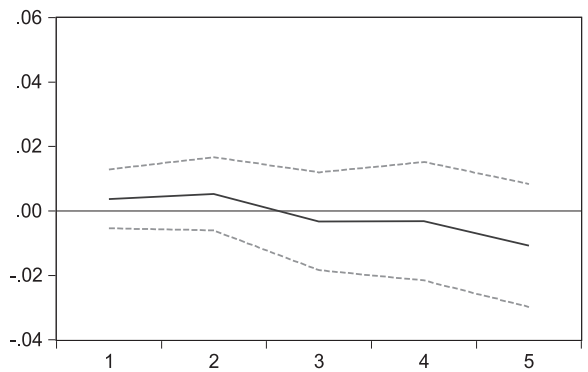

Response of LPIBNT to LXPT

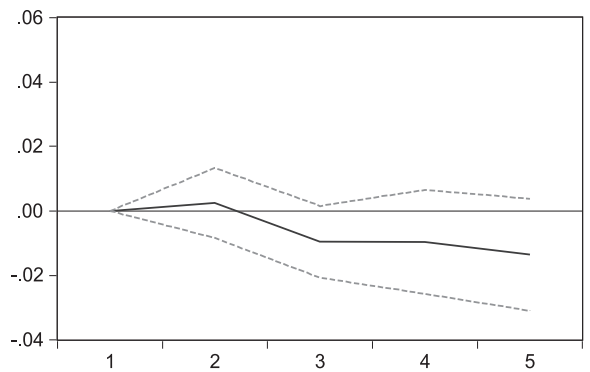

mientras que cuando aumentan las exportaciones primarias el efecto sobre el PIB es mínimo en los primeros dos periodos, pero después comienza a volverse negativo, aunque su efecto es muy cercano a cero. 
En cuanto al capital, se observa que choques positivos sobre esta variable generan variaciones positivas sobre el PIB neto durante los dos primeros periodos, posteriormente el efecto se va disipando en el tiempo. Por su parte, crecimientos en el trabajo no generan estadísticamente impactos sobre el PIB neto.

Los resultados de las pruebas anteriores evidencian la necesidad que tiene el departamento de Boyacá de dinamizar las exportaciones, especialmente las industriales y primarias, ya que tienen un efecto positivo sobre el crecimiento del producto departamental.

\section{CONCLUSIONES}

A pesar de la gran cantidad de tratados de libre comercio que ha firmado el país, no existen en el departamento de Boyacá estudios serios que relacionen el crecimiento y el comercio internacional. Este hecho motivó la elaboración de un estudio detallado de la oferta exportadora departamental y su relación con el producto interno de Boyacá, a través de la conocida hipótesis de crecimiento liderado por exportaciones. En tal sentido cobra importancia el rol del sector externo, los tratados de libre comercio y de la política comercial como mecanismos dinamizadores de la producción, la inversión y el empleo en Boyacá.
La oferta exportable de Boyacá proviene básicamente del sector primario. En 1980 representaba el $96 \%$, que corresponde a bienes mineros, especialmente esmeraldas y carbón coque. Dicha situación no ha cambiado con el paso del tiempo, incluso se ha incrementado al $99 \%$ para el año 2015. Por su parte, el índice de apertura económica (importaciones más exportaciones sobre PIB) del departamento de Boyacá es relativamente bajo ( $2 \%$ en 1980 y $12 \%$ en 2015), lo que revela que es un departamento poco abierto al comercio comparado con otros departamentos de Colombia. Igualmente, la participación de las exportaciones industriales hoy es más baja que hace 30 años. Para los ochenta representaba, en promedio, un $5 \%$ de las exportaciones totales, en los últimos años (en lo corrido de este siglo) participan con un $1,4 \%$.

Para el período comprendido entre 1980 y 2015; es decir, en los últimos 35 años, el crecimiento promedio del producto interno bruto del departamento de Boyacá fue apenas del $2,6 \%$, cifra inferior al crecimiento nacional, que fue del 3,6 $\%$. Por su parte, la tasa de crecimiento promedio de las exportaciones para el mismo período se ubicó en un $35 \%$, cifra global que indica intuitivamente que el sector exportador ha tenido un mejor desempeño y que, por tanto, ha respondido mejor a las exigencias de una economía más expuesta al comercio exterior. 
Boyacá es un departamento con vocación agrícola; sin embargo, la producción de dicho sector se dirige, en su gran mayoría, al mercado interno. Se destacan las exportaciones de papa y flores. Por su parte, las ventas externas de bienes agroindustriales ocupan un lugar marginal en la oferta exportadora del departamento. Su participación en las exportaciones totales es muy pequeña, en promedio representan el $0,11 \%$. Se destacan los rubros de azúcares y artículos de confitería, especialmente la preparación de jarabes y dulces. En el rubro de preparación de hortalizas están las compotas, los jugos y purés. Los anteriores datos reflejan el poco valor agregado que se le añade a los productos agroindustriales que utilizan materias primas del sector agrícola. En el sector industrial, la siderurgia tiene una presencia importante en el departamento y parte de su producción se exporta con productos derivados del hierro y el acero. Igualmente se destaca la fabricación y exportación de muebles de madera.

La prueba de causalidad vectorial de Granger para el modelo que tiene como variable dependiente el logaritmo del PIB neto arroja que, en conjunto, las variables escogidas causan en el sentido Granger al PIB, especialmente las exportaciones industriales (LXIT) y las exportaciones primarias (LXPT), lo cual prueba la hipótesis de crecimiento fundamentado en exportaciones. Los resultados de las pruebas anteriores sugieren que el departamento debe desarrollar una política exportadora donde se estimule el comercio exterior de productos de origen manufacturero y primario principalmente. 
Apuntes CENES Volumen 37, Número 65

enero - junio 2018. Págs. 175-211

\section{REFERENCIAS}

Agosín, M. R. (1999, agosto). Comercio y crecimiento en Chile. Revista de la CEPAL, (68), 79-100.

Alonso, J. \& Patiño, C. (2007, julio) ¿Crecer para exportar o exportar para crecer? El caso del Valle del Cauca. Ensayos sobre Economía Regional, (46), 1-22. Recuperado de http://www.banrep.gov.co/publicaciones/pub_ec_reg2.htm\#Cali.pdf.

Arévalo, W. (2004). El tratado de libre comercio TLC y el crecimiento regional. Apuntes del CENES, 24(38), 192-193.

Balassa, B. (1978, June). Exports and Economic Growth: Further Evidence. Journal of Development Economics, 5(2), 181-189.

Balassa, B. (1985). Exports, Policy Choices, and Economic Growth in Developing Countries after the 1973 Oil Shock. Journal of Development Economics, 18(1), 23-35.

Banco de la República -Grupo de Estudios sobre Crecimiento Económico GRECO- (2002). El crecimiento económico colombiano en el Siglo XX. Bogotá: Fondo de Cultura Económica.

Cáceres, W. (2013). Las exportaciones y el crecimiento económico en Colombia 1994-2010. Tesis de Maestría, Universidad Nacional de Colombia. Bogotá.

Comisión Económica para América Latina y el Caribe -CEPAL- (2004). Desarrollo productivo en economías abiertas. Santiago de Chile: CEPAL.

Cuadros, A. (2000, enero-junio). Exportaciones y crecimiento económico: un análisis de causalidad para México. Estudios Económicos, 15(1).

Dane (2016). Dirección de Difusión, Mercadeo y Cultura Estadística. Bogotá D.C: Dane.

Dickey, D \& Fuller, W (1979). Distribution of the Estimators for Autoregression Time Series with a Unit Root. Journal of the American Statistical Association. Vol 74, 427-431. 
Esguerra, M., Montes, E., Garavito, A. \& Pulido, C. (2010). El comercio colombo-venezolano: características y evolución reciente. Borradores de Economía, (602), 1-49. Recuperado de http://www.banrep.gov.co/sites/default/ files/publicaciones/pdfs/borra602.pdf.

Feder, G. (1982, febrero). On Exports and Economic Growth. World Bank Staff, Working Paper, (508), 1-24. Retrieved from http://documents.worldbank.org/curated/en/866581468331053546/pdf/REP372000Expor0r0the019730oil0shock.pdf.

Fourastié, J. (1956). La gran esperanza del siglo XX. Barcelona: Luis Miracle.

Granger, C. (1969). Investigating Causal Relations by Econometric Models and Cross-spectral Methods. Econométrica, 37, 424-438.

Jin, J. (2002). Exports and Growth: Is the Export-Led Growth Hypothesis Valid for Provincial Economies? Applied Economics, 34(1), 63-76. https://doi. org/10.1080/00036840010025632

Johansen, S. (1988). Statistical Analysis of Cointegrating Vectors. Journal of Economic Dynamics and Control. 12, 231-254.

Kalecki, M. (1977). Ensayos escogidos sobre dinámica de la economía capitalista. México, D.F.: Fondo de Cultura Económica.

Kaldor, N. (1961). Ensayos sobre desarrollo económico. México: Centro de Estudios Monetarios Latinoamericanos.

Kuznets, S. (1973). Crecimiento económico moderno. Madrid: Aguilar.

Ljungwall, C. (2006). Export-Led Growth: Application to China's Provinces, 1978-2001. Journal of Chinese Economic and Business Studies, 4(2), 109126. https://doi.org/10.1080/14765280600736866

Myrdal, G. (1959). Teoría económica y regiones subdesarrolladas. México: Fondo de Cultura Económica.

Ohlin, B. (1948). Comercio exterior y política comercial. Madrid: Aguilar. 
Pardo, A. \& Meller, P. (2002). El rol de las exportaciones en el crecimiento económico regional. En Documentos de Trabajo No. 143. Chile: Centro de Economía aplicada (CEA) Universidad de Chile. Recuperado de http:// www.dii.uchile.cl/ cea/sitedev/cea/www/download.php?file=documentos_trabajo/ASOCFILE120030326141624.pdf.

Phillips, P. \& Perron, P. (1988). Testing for a United Root in Time Series Regression. Biométrika. 75, 335-346.

Prime, P. \& Park, J. (1997). Export Performance and Growth in China: A Cross-Provincial Analysis. Applied Economics, 29(10), 1353-1363. https://doi.org/10.1080/00036849700000026

Ricardo, D. (1985). Principios de economía política y tributación I. Barcelona: Orbis.

Richardson, H. (1977). Teoría del crecimiento regional. Madrid: Pirámide.

Richardson, H. (1986). Economía regional y urbana. Madrid: Alianza.

Ringsrud, R. (2013). Esmeraldas, una guía apasionada. Bogotá: Maremágnum.

Sánchez, F. \& Rocha, R. (2000). Exportaciones en Colombia: patrones de inserción y obstáculos estructurales en los años 90. En R. Rocha \& M. Olarreaga (comp.), Las exportaciones colombianas en la apertura. Bogotá: Centro Editorial Universidad del Rosario e Instituto del Banco Mundial.

Siliverstovs, B. \& Herzer, D. (2006). Export-Led Growth Hypothesis: Evidence for Chile. Applied Economics, 13(5), 319-324. https://doi. org/10.1080/13504850500407293

Smith, A. (1994). Investigación sobre la naturaleza y causas de la riqueza de las naciones. México, D.F.: Fondo de Cultura Económica. 
Las exportaciones y el crecimiento económico en Boyacá Colombia 1980-2015

Willyam Cáceres-Rodríguez - Omaira Inés Agudelo-Cely - Ricardo Alonso Tejedor-Estupiñán

\section{ANEXO 1}

Series utilizadas para las regresiones

\begin{tabular}{|c|c|c|c|c|c|}
\hline Años & $\mathbf{P I B N}_{t}$ & $\mathbf{K}_{t}$ & $\mathbf{L}_{t}$ & $\mathbf{X P t}$ & XIt \\
\hline 1980 & 5.855 & 3.514 & 11.487 & 30.871 .249 & 1.128 .238 \\
\hline 1981 & 5.558 & 13.225 & 11.213 & 46.066 .177 & 2.242 .952 \\
\hline 1982 & 5.623 & 11.079 & 10.375 & 42.005 .423 & 2.048 .917 \\
\hline 1983 & 5.551 & 241.201 & 9.840 & 54.836 .343 & 3.541 .163 \\
\hline 1984 & 5.730 & 59.043 & 8.760 & 63.240 .759 & 4.220 .248 \\
\hline 1985 & 5.767 & 44.152 & 7.487 & 115.584 .120 & 3.764 .815 \\
\hline 1986 & 6.077 & 57.848 & 7.460 & 289.197 .384 & 11.350 .957 \\
\hline 1987 & 6.401 & 519.467 & 7.588 & 726.117 .304 & 23.704 .726 \\
\hline 1988 & 6.639 & 125.305 & 7.685 & 1.732 .948 .993 & 184.986.152 \\
\hline 1989 & 6.790 & 900.465 & 7.459 & 3.339 .367 .672 & 120.288 .527 \\
\hline 1990 & 7.044 & 25.658 & 7.329 & 6.026 .243 .323 & 369.742 .406 \\
\hline 1991 & 7.134 & 160.232 & 6.851 & 11.480 .061 .526 & 1.700 .258 .268 \\
\hline 1992 & 7.283 & 2.679 .731 & 7.198 & 19.691 .774 .149 & 721.123 .399 \\
\hline 1993 & 8.302 & 1.287 .721 & 7.310 & 66.404 .449 .113 & 45.565 .405 \\
\hline 1994 & 7.893 & 6.222 .938 & 7.227 & 92.138 .269 .642 & 313.435 .661 \\
\hline 1995 & 7.973 & 12.823 .011 & 7.396 & 129.105 .106 .524 & 3.009 .273 .830 \\
\hline 1996 & 7.768 & 2.059 .530 & 6.647 & 70.620 .494 .278 & 146.865 .053 \\
\hline 1997 & 7.973 & 2.665 .271 & 7.223 & 74.905 .997 .857 & 135.609 .055 \\
\hline 1998 & 7.614 & 3.363 .203 & 6.150 & 70.415 .073 .273 & 585.933 .444 \\
\hline 1999 & 7.589 & 4.147 .483 & 5.591 & 122.250 .295 .815 & 1.718.569.834 \\
\hline 2000 & 7.806 & 5.037 .183 & 5.776 & 187.741 .203 .536 & 3.572 .490 .272 \\
\hline 2001 & 7.767 & 5.742 .953 & 5.455 & 185.654.578.858 & 2.705.328.628 \\
\hline 2002 & 7.916 & 6.492 .692 & 5.730 & 201.072.202.887 & 1.768.328.689 \\
\hline 2003 & 8.169 & 7.494 .976 & 5.049 & 222.053 .053 .907 & 1.732.631.953 \\
\hline 2004 & 8.072 & 8.508 .839 & 5.948 & 237.704.298.818 & 4.296.140.838 \\
\hline 2005 & 8.471 & 9.596 .598 & 5.606 & 245.347 .841 .687 & 4.735.594.919 \\
\hline 2006 & 8.771 & 45.556 .393 & 6.239 & 360.627 .167 .582 & 6.138 .856 .017 \\
\hline 2007 & 9.935 & 157.412 .907 & 6.433 & 381.823 .826 .829 & 4.465.289.132 \\
\hline 2008 & 10.302 & 148.467 .337 & 6.254 & 734.575 .026 .883 & 22.160 .686 .813 \\
\hline 2009 & 10.639 & 155.828 .164 & 6.266 & 505.519 .066 .243 & 16.793 .083 .005 \\
\hline 2010 & 10.706 & 134.451 .717 & 6.009 & 859.408 .452 .739 & 9.300 .195 .623 \\
\hline 2011 & 11.786 & 71.119 .937 & 6.091 & 862.574 .748 .476 & 9.290 .444 .321 \\
\hline 2012 & 12.065 & 76.991 .724 & 5.860 & 975.334 .579 .593 & 9.498 .009 .842 \\
\hline 2013 & 12.501 & 81.994 .448 & 5.642 & 910.622 .998 .786 & 4.240 .539 .185 \\
\hline 2014 & 12.915 & 87.586 .081 & 5.946 & 1.049.217.692.275 & 9.634 .023 .077 \\
\hline 2015 & 13.057 & 93.712 .133 & 6.318 & 1.275 .738 .180 .051 & 5.899 .423 .564 \\
\hline
\end{tabular}




\section{ANEXO 2}
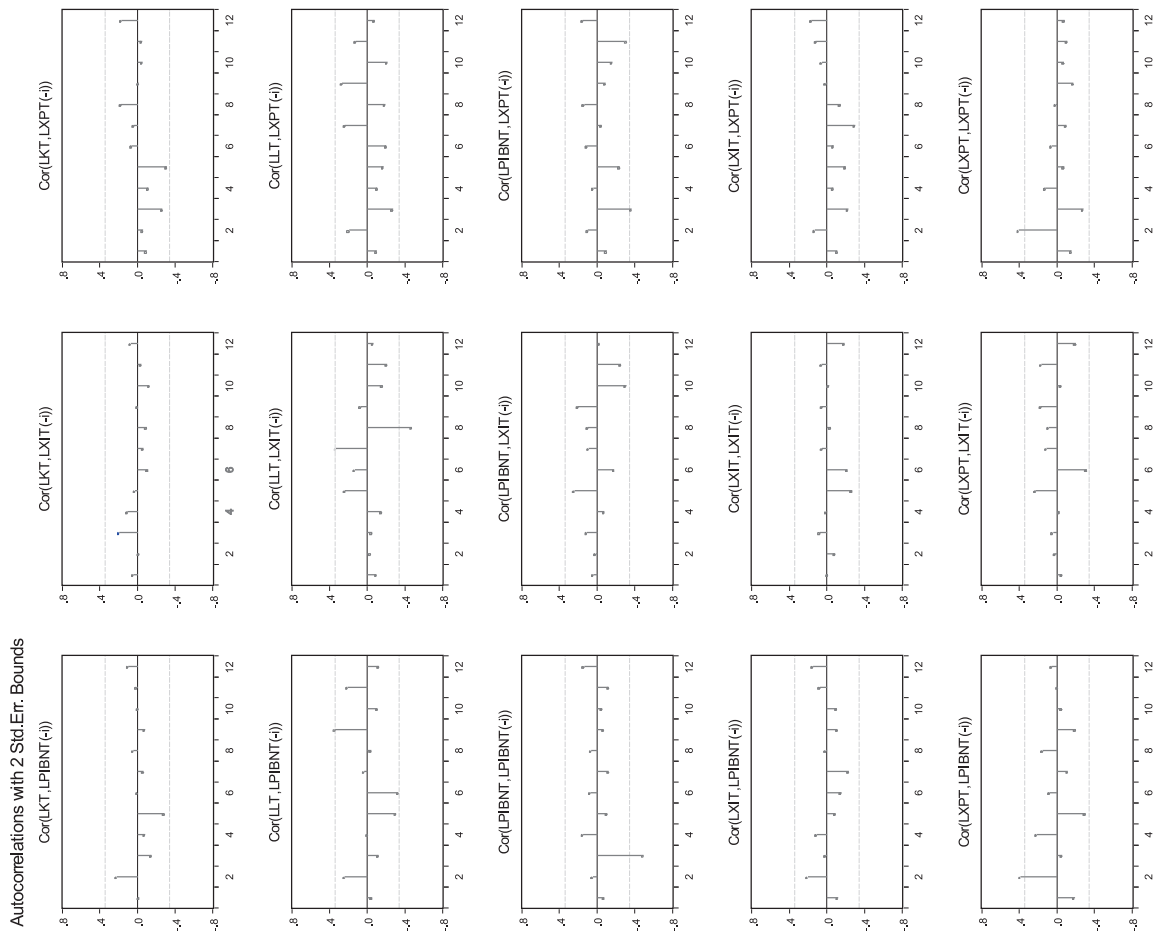

守
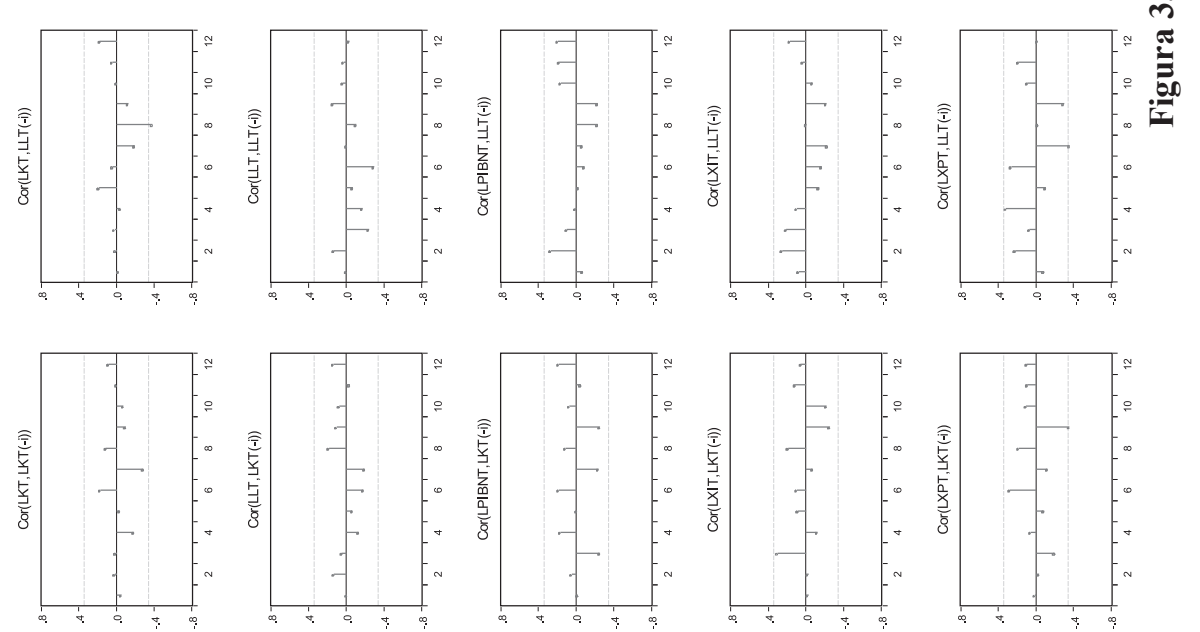